\title{
EL CONCEPTO Y LA JUSTIFICACIÓN DEL PATERNALISMO
}

\author{
Macario Alemany
}

Universidad de Alicante

RESUMEN. Este artículo se divide en dos partes. En la primera parte, el autor interviene en la discusión sobre el concepto de paternalismo proponiendo que ésta se ponga en relación con la teoría del poder. A su juicio, los casos más claros de paternalismo serían ejercicios de poder y los casos dudosos se situarían en los límites del poder: por ejemplo, serían casos de mera influencia. Quien ejerce el poder sobre otros puede ser responsabilizado de las consecuencias de este ejercicio; esta posibilidad de exigir responsabilidad explica la necesidad de justificación del comportamiento paternalista. Sobre dicha justificación, en la segunda parte, el autor propone una serie de condiciones que deberían cumplirse, fundamentalmente en el contexto del paternalismo del Estado con sus ciudadanos, para poder afirmar que una concreta interferencia paternalista está justificada. Entre dichas condiciones destaca la exigencia de una situación de incompetencia básica de la persona tratada paternalistamente.

\begin{abstract}
This article is divided into two parts. In the first, the author enters into the discussion on the concept of paternalism, proposing that it should be related to the theory of power. As he sees it, the clearest cases of paternalism are cases where power is exercised and the doubtful ones are those found in the limits of power: for example, they are cases of mere influence. He who exercises power over others can be made responsible for the consequences of this action; the fact that responsibility can be required explains the necessity for the justification of paternalistic behaviour. In the second part, with reference to this justification, the author proposes a number of conditions which should be met, basically in the context of the State's paternalism with its citizens, in order to be able to state that a specific paternalistic intervention is justified. Of these conditions, the one that stands out is the requirement that the person who is treated in a paternalistic way should be in a situation of basic incompetence.
\end{abstract}




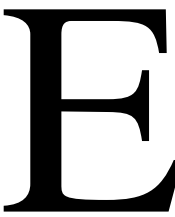

ste artículo trata sobre el paternalismo en general y, en especial, sobre el paternalismo jurídico. La noción de paternalismo apunta a una extrapolación del modelo de relación paternofilial a otro tipo de relaciones sociales: por ejemplo, la relación entre el Estado y sus ciudadanos o entre el médico y el paciente. En particular, la analogía se construye no tanto sobre el aspecto del cuidado, como sobre el aspecto del control que entraña el ejercicio de la paternidad. Es la aplicación del modelo del poder paternal (la patria potestas) a otros ámbitos sociales lo que se cuestiona.

El problema del paternalismo tiene una importante dimensión práctica. El ejercicio de cualquier responsabilidad cuyo cumplimiento, parcial o totalmente, se oriente a promover o proteger el bienestar individual de otros pone de manifiesto que este bienestar puede ser amenazado por los propios individuos. Ésta es una experiencia común entre los legisladores, médicos, asistentes sociales, profesores, abogados, etc. La lucha contra la enfermedad, por ejemplo, se ve frustrada en muchas ocasiones por los hábitos de vida no saludables: pensemos en el consumo de tabaco, la mala alimentación o el sedentarismo. Me atrevería a decir que el paternalismo es una posibilidad abierta y con frecuencia practicada en cualquier ámbito de responsabilidad pública que se relacione directamente con el bienestar individual.

Frente a esta realidad, la ideología dominante en los países industrializados es claramente anti-paternalista. El valor otorgado a la autonomía individual, a la democracia e, incluso, al sistema de libre mercado parecen descartar la posibilidad de encontrar supuestos de paternalismo justificado. Sin embargo, la persistente presencia de intervenciones que se nos presentan como plausiblemente justificadas, por un lado, y como paternalistas, por otro, desafían a esta corriente de pensamiento. El paternalismo adquiere, por ello, una extraordinaria relevancia teórica. A mi juicio, las implicaciones de la justificación del paternalismo constituyen, junto con una consideración profunda del alcance del principio de daño a terceros, una poderosa herramienta contra las diferentes teorías del Estado mínimo que emanan de esa fuente de muchos caños en que se ha convertido el liberalismo político.

\section{El concepto de paternalismo}

El concepto de paternalismo ha sido objeto de una larga y compleja discusión que comienza en el principio de los años setenta del pasado siglo y se prolonga durante dos décadas sin arrojar resultados concluyentes ${ }^{1}$. Todas

\footnotetext{
${ }^{1}$ En el origen de esta discusión hay dos artículos fundacionales: En primer lugar, "Paternalism”, de Gerald Dworkin, publicado en Wasserstrom, R. A. (ed.): Morality and the Law, ed. Wadsworth Publishing Co., Belmont, 1971, pp. 107-126 (reeditado en The Monist 56, $\mathrm{n}^{\circ}$
} 
las propuestas conceptuales en torno al paternalismo tienen como mínimo común denominador la que podríamos denominar "analogía paternalista”, es decir, una semejanza de relaciones en la que el foro de la analogía lo constituye la bien conocida relación paterno-filial y el tema lo constituye la relación soberano-súbdito, patrón-obrero, médico-paciente, etc. Sin embargo, hay notables discrepancias sobre cómo construir la analogía, qué definición es la más apropiada y, en particular, sobre qué relevancia darle al carácter peyorativo que en el lenguaje ordinario tiene el término "paternalismo”.

No entraré a explicar las diferentes propuestas de definición de "paternalismo” que se han hecho, puesto que ello me ocuparía demasiado espacio para los objetivos de este artículo. Me limitaré, por tanto, a exponer algunas ideas sobre el concepto de paternalismo (al menos, sobre un concepto central de paternalismo).

\subsection{La neutralidad valorativa del concepto de paternalismo}

El primer problema que se enfrenta en el estudio del concepto y la justificación del paternalismo es la emotividad normalmente desfavorable del término en el lenguaje ordinario. Ahora bien, incluso para los que hacen un uso peyorativo del término "paternalismo”, éste no designaría un concepto puramente normativo (como, por ejemplo, ‘malo' o ‘incorrecto'), por lo que es posible separar algunos aspectos descriptivos de los puramente evaluativos. Siendo así, a mi juicio, como punto de partida no debería hacerse de la valoración del paternalismo (justificado o injustificado) una "característica que define”, sino tan sólo "una característica que acompaña”2. De esta manera, se evita el riesgo de dar con soluciones a problemas morales que descansen en definiciones, pues resulta inaceptable que se le dé una respuesta

1 (1972), pp. 64-84; en Sartorius, Rolf: Paternalism, ed. University of Minnesota Press, Minneapolis, 1987, pp. 19-34; y en Feinberg, Joel y Jules Coleman (eds.): Philosophy of Law, ed. Wadsworth, Belmont, 2000, pp. 271-280; existe una traducción del mismo al castellano realizada por Jorge M. Seña e incluida en la colección de ensayos: Derecho y Moral. Ensayos analíticos, editada por Jerónimo Betegón y Juan Ramón de Páramo, publicada en 1990). En segundo lugar, “Legal Paternalism”, de Joel Feinberg, publicado en Canadian Journal of Philosophy 1, nº1 (1971), pp. 106-24 (reeditado en Sartorius, Rolf: Paternalism, cit., pp. 3-18). En el ámbito de la filosofía en español, cabe destacar los siguientes trabajos: Garzón Valdés, Ernesto: “¿Es éticamente justificable el paternalismo jurídico?, en Doxa 5(1988), pp. 155-173; Nino, Carlos S.: Ética y derechos humanos, ed. Ariel, Barcelona, 1989, pp. 413 y ss.; Atienza, Manuel: “Discutamos sobre paternalismo”, en Doxa 5(1988), pp. 203-214; Dieterlen, Paulette: “Paternalismo y Estado de Bienestar”, en Doxa 5(1988), pp. 175-194; Díaz Pintos, Guillermo: Autonomía y paternalismo, ed. Universidad de Castilla La Mancha, Murcia, 1993; y Salcedo Megales, Damián: Autonomía y bienestar (La ética del Trabajo Social), ed. Comares, Granada, 2001.

${ }^{2}$ Sobre esta distinción, véase: Hospers, John: An Introduction to Philosophical Analysis, ed. Routledge, London, 1990. 
negativa al problema de si es correcto desde el punto de vista moral ejercer el paternalismo, diciendo que se trata precisamente de "paternalismo” y el "paternalismo” por definición está injustificado. Entiendo, en consecuencia, que el concepto de paternalismo es "neutral” cuando la afirmación “A ejerce paternalismo sobre B” no conlleva necesariamente el juicio moral “A está actuando inmoralmente con respecto a B”.

\subsection{Elementos de la acción paternalista}

En la elucidación del concepto de paternalismo me parece que el punto de partida más adecuado es tratar de aclarar el significado de la expresión $A$ ejerce paternalismo sobre B. La acción paternalista de A sobre B se caracterizará por medio de dos elementos: el modo y la finalidad. El tercer elemento, los sujetos A y B, nos servirá para analizar algunos tipos fundamentales de paternalismo.

\subsubsection{El modo}

El elemento de la relación paternalista que, sin duda, mayores dificultades crea en su análisis conceptual es el del modo propio de la acción paternalista. El paternalismo se diferenciaría de la conducta meramente benevolente porque consiste, según los autores, en coaccionar, interferir con la libertad, faltar al respeto debido, violar la autonomía, engañar, ocultar información, violar normas morales, etc. Si partiéramos de un tipo de definición como el de la definición por género y diferencia específica, podríamos decir que el problema del paternalismo no se plantea en torno a su adscripción al género (de los actos benevolentes) sino en determinar cuál es su diferencia específica. Y esa diferencia estaría en el modo en que se ejerce ese acto benevolente.

En mi opinión, estas dificultades para encerrar en una definición a la acción paternalista tienen su origen en que el paternalismo supone un ejercicio de poder de A sobre $\mathrm{B}$ y, en consecuencia, la caracterización del paternalismo estaría contagiada de los problemas que se suscitan al tratar de definir "poder”, un concepto muy controvertido. Los puntos críticos de discrepancia entre los autores en torno al modo propio de la intervención paternalista serían un reflejo de puntos críticos de discusión en la teoría del poder. En particular, la dificultad para distinguir adecuadamente entre las nociones de "poder” y de "influencia” habría hecho fracasar los esfuerzos sobre la elucidación conceptual del paternalismo.

Señalar la causa de la polémica interminable sobre el concepto de paternalismo es una modesta aportación y no pretendo ir mucho más allá. Tan sólo quisiera explicitar algunas implicaciones de esta propuesta -que el paternalismo constituye un ejercicio de poder-, apoyándome en el profundo 
y esclarecedor estudio sobre los conceptos de poder e influencia de Ruth Zimmerling ${ }^{3}$.

Esta autora define al "poder social” como la capacidad para obtener resultados deseados haciendo a otros hacer lo que uno quiere"4; mientras que la "influencia social” sería la "capacidad para afectar las creencias de otros"5. Hay cuatro ideas en la aproximación de Zimmerling que me parecen importantes para el tema del paternalismo: el ejercicio del poder se orienta a obtener intencionalmente (I) un comportamiento de otro (II); es posible ejercer el poder por medio de ejercer influencia (III); y el ejercicio del poder conlleva responsabilidad por parte de quien lo ejerce, aun cuando el poder se ejerce por medio de ejercer influencia (IV). A continuación, comentaré brevemente cada una de estas ideas.

(I) Creo que la mayoría de los autores estarían de acuerdo en que la acción paternalista es una acción intencional. Si bien tanto el poder como la influencia pueden ser ejercidos intencionalmente, el poder, a diferencia de la influencia, es siempre ejercido intencionalmente. Los casos de ejercicio de influencia no intencional podrían ser mejor descritos, de acuerdo con Zimmerling, diciendo que alguien es (o ha sido) influyente (éste sería el sentido de influencia que se utilizaría al señalar que "los escritos de Marx han influido en muchos autores del siglo XX”)

(II) Si la finalidad del paternalismo es evitar que B lleve a cabo acciones u omisiones que le dañan a sí mismo y/o le suponen un incremento del riesgo de daño, entonces la acción paternalista se orienta a obtener un comportamiento de B y constituye (de tener éxito) un ejercicio de poder. La controversia sobre el carácter paternalista de algunos ejemplos de paternalismo tiene su origen precisamente en que se tratarían de supuestos de ejercicio de influencia que no son ejercicio de poder: por ejemplo, el caso en el que un médico miente a una anciana en su lecho de muerte sobre el trágico destino de su hijo desaparecido con la única finalidad de evitarle un sufrimiento añadido ${ }^{7}$.

\footnotetext{
${ }^{3}$ Véase: Zimmerling, Ruth: Influence and Power (Variations on a Messy Theme), ed. Kluwer, 2005.

${ }^{4}$ Zimmerling, Ruth: Influence and Power (Variations on a Messy Theme), cit., p. 141.

${ }^{5}$ Ibídem.

${ }^{6}$ Zimmerling, Ruth: Influence and Power (Variations on a Messy Theme), cit., p. 145.

${ }^{7}$ Se trata de un ejemplo que muestra, de acuerdo con Bernard Gert y Charles M. Culver, que hay casos de paternalismo en los que no se trata de influir en el comportamiento de la gente sino en sus sentimientos. Este ejemplo, entre otros, ha llevado a Gert y Culver a sostener que el único elemento común a todas las intervenciones benevolentes que suelen denominarse "paternalistas” es que se constata en la acción la violación de normas morales. Véase: Gert, Bernard y Charles M. Culver: “Paternalistic Behavior”, Philosophy \& Public Affairs 6(1976), vol. 1, pp.
} 
(III) De acuerdo con nuestra autora, el poder puede ser ejercido sobre otro de las siguientes maneras: 1) por medio de afectar un existente estado de cosas de tal manera que, dadas ciertas creencias normativas y empíricas del otro, hay un cambio en sus preferencias efectivas que le inducen a actuar del modo deseado; 2) afectando las creencias empíricas de alguien de tal manera que, dadas sus creencias normativas y sus preferencias, llegará a creer que la acción deseada por el otro es la más adecuada para satisfacer sus propias preferencias; y 3) afectando las creencias normativas de alguien de tal manera que, dadas sus creencias empíricas y sus preferencias, llegará a creer que la acción deseada es la que puede -o debe- llevar a cabo ${ }^{8}$. (2) y (3) son ejercicios de poder por medio de ejercer influencia, lo que tienen en común con (1) es que se orientan a obtener un comportamiento.

(IV) La definición del paternalismo como un ejercicio de poder creo que ilumina el problema fundamental de este concepto, esto es, la cuestión de por qué el paternalismo constituye un problema moral si es una conducta esencialmente benevolente. La respuesta estaría en que siempre que A ejerce el poder sobre B se abre la posibilidad de responsabilizar a A por lo que B ha hecho. Es esta posibilidad abierta y no tanto los concretos medios de que se vale A (con respecto a los cuales se pueden plantear específicos problemas de justificación: por ejemplo, cuando se ejerce el poder por medio de la coacción) el mínimo común denominador de los muy variados ejemplos que suelen presentarse de paternalismo.

\subsubsection{La finalidad}

De acuerdo con lo anterior, un acto paternalista sería un ejercicio de poder de A orientado a obtener cierto comportamiento de B. Ahora bien, no todo ejercicio de poder es paternalista y, por tanto, necesitamos precisar más el concepto. Lo que distinguiría al paternalismo de otros ejercicios de poder es que la finalidad del mismo es evitar daños a B o, más específicamente, conseguir que B se comporte de manera que se evite daños y, además, daños de tipo físico, psíquico y/o económico: por ejemplo, obligar a B a dejar de fumar para disminuir el riesgo de cáncer.

Esta precisión conceptual conlleva una doble restricción: primera, el paternalismo consistiría en “evitar daños” y no en "beneficiar” y, segunda, el paternalismo consistiría en evitar daños de tipo físico, psíquico o económico y no daños de otro tipo, en particular, daños morales. Una doble restricción que está justificada en parte porque refleja el uso que se ha hecho del tér-

45-57; y Culver, Charles M. y Bernard Gert: Philosophy in Medicine (Conceptual and Ethical Issues in Medicine and Psychiatry), ed. Oxford University Press, Nueva York, 1982.

${ }^{8}$ Zimmerling, Ruth: Influence and Power (Variations on a Messy Theme), cit., p. 143. 
mino paternalismo en la discusión académica y en parte por el propósito de separar los problemas de justificación del paternalismo de los problemas de justificación del denominado perfeccionismo.

El término "beneficiar" o la expresión "poder benevolente" se usan en un sentido genérico que engloba a las acciones que tratan de "evitar daños", pero se usa también en un sentido específico de "beneficiar" que se opone a la idea de "evitar daños”. Este sentido específico de "beneficiar” sería el utilizado cuando, por ejemplo, se considera que una operación de cirugía estética orientada a embellecer es un "beneficio", mientras que una operación quirúrgica para extraer un tumor maligno es “evitar un daño”. Una forma de dar sentido a esta distinción es por medio de la delimitación de unos “intereses del bienestar” o "necesidades básicas” de los seres humanos. La afectación negativa a un interés del bienestar o la insatisfacción de una necesidad básica supone situar al individuo por debajo de un umbral mínimo de bienestar a partir del cual todos sus demás intereses declinan irremediablemente. De ahí que “evitar daños” a un individuo sea tanto llevar el grado de satisfacción de sus intereses por encima de dicho umbral mínimo como evitar que caigan por debajo de este umbral. Sobre esta concepción objetivista de los intereses implicada en las nociones de "interés del bienestar" o de "necesidad básica” se construyen la mayorías de las políticas públicas de bienestar que, con frecuencia, han sido calificadas de paternalistas: sanidad pública, educación obligatoria, seguridad social en general, etc.

Más allá de los intereses de bienestar los individuos tienen intereses ulteriores que dependen de sus propias creencias y deseos, con respecto a los cuales es plausible concebir acciones paternalistas. De ahí que algunos autores, como Carlos S. Nino, hayan señalado que el paternalismo se orientaría no sólo a la satisfacción de las necesidades básicas sino también a hacer posible los propios planes de vida que los individuos han elegido libremente ${ }^{10}$. Así, por ejemplo, la acción orientada a que un estudiante de doctorado no abandone su proyecto de tesis doctoral en un momento de flaqueza podría ser, dadas otras circunstancias, candidata a la calificación de paternalista.

Si la finalidad propia del paternalismo consistiría en "evitar daños” en los sentidos que se acaban de aludir, por contraposición, a otra figura distinta le correspondería la finalidad de beneficiar. Dichos "beneficios" consistirían en la promoción de esos intereses del bienestar más allá de su umbral mínimo y, en general, en la promoción de intereses ulteriores que

\footnotetext{
${ }^{9}$ Sobre este tema, véase: Feinberg, Joel: Harm to Others (The Moral Limits of the Criminal Law), ed. Oxford University Press, Oxford, 1984, pp. 31 y ss., y pp. 139 y ss.; y Von Wright, G. Henrik: Norma y Acción (Una investigación lógica), ed. Tecnos, Madrid, 1979, p. 47 y ss.

${ }^{10}$ Nino, Carlos S.: Ética y derechos humanos, cit., p. 142.
} 
los individuos no reconocen como tales. Cuando esta finalidad se persigue ejerciendo el poder sobre los sujetos que se trata de "beneficiar" estaríamos ante lo que suele denominarse "perfeccionismo". El perfeccionismo muestra una doble dimensión, maximizadora (de beneficios) y moralista, que le distingue del paternalismo, minimizadora (de daños) y orientado al bienestar. Para ilustrar este punto se pueden proponer algunos ejemplos de ejercicios de poder paternalista y perfeccionista: hacer obligatoria la educación general básica sería paternalista mientras que imponer una educación esmerada en, por ejemplo, bellas artes sería perfeccionista; imponer una rehabilitación para curar una lesión física sería paternalista mientras que hacer obligatoria la práctica del deporte podría ser considerado perfeccionista; prohibir el consumo de drogas para evitar daños a la salud del consumidor sería paternalista, mientras que hacerlo porque la vida con drogas se considera, con independencia de los daños a la salud que implique, inferior a la vida sin drogas sería perfeccionista.

Si se acepta la tesis del carácter moralizante y maximizador del perfeccionismo, éste se distinguiría de otra figura, que sería el ejercicio del poder orientado a evitar daños morales a los individuos. Algunas propuestas de prohibir el consumo de pornografía han pretendido perseguir la finalidad de evitar a los potenciales consumidores daños morales, es decir, el daño de un carácter moral degradado ${ }^{11}$. Esta figura no estaría en el centro de los problemas que se suelen discutir bajo el epígrafe de "paternalismo”, aunque podría ser considerada una forma de paternalismo moralista o de moralismo paternalista. Mi propuesta es, en todo caso, restringir el uso del término paternalismo a la evitación de daños físicos, psíquicos y/o económicos, en parte por seguir los criterios del uso ordinario del término y en parte porque, como ha señalado Joel Feinberg, no es cierto que la degradación moral constituya necesariamente un daño para el individuo (lo será si el individuo tiene un interés particular en la excelencia moral o si, en las circunstancias sociales, tal degradación puede producir en el individuo daños de otro tipo y éste carece de la astucia compensatoria para evitarlo) ${ }^{12}$.

Por último, con respecto a la finalidad del paternalismo conviene insistir en que ésta consiste específicamente en evitar daños a los individuos autoinfligidos o infligidos por otro pero con el consentimiento o a requerimiento del dañado. Esta última precisión presupone que (1) existen actos de autodaño que son puramente auto-referentes o, al menos, que son directamente auto-referentes y sólo indirectamente (e irrelevantemente desde el punto de

${ }^{11}$ Sobre este tema, véase: Malem Seña, Jorge F.: "Pornografía y feminismo radical”, en Doxa 12 (1992), pp. 177-211.

${ }^{12}$ Véase: Feinberg, Joel: Harm to Others, cit., pp. 65 y ss. 
vista moral) hetero-referentes ${ }^{13}$ y (2) que si bien parece plausible afirmar que nadie comete injusticia contra sí mismo, no es cierto que nadie pueda perjudicarse a sí mismo ${ }^{14}$.

\subsubsection{Una plausible definición de paternalismo}

De acuerdo con lo expuesto, la siguiente podría ser una definición plausible del paternalismo:

El agente A ejerce paternalismo sobre B si y sólo si:

1) A ejerce poder sobre $B$,

2) con la finalidad de evitar que B lleve a cabo acciones u omisiones que le dañan a sí mismo y/o le suponen un incremento del riesgo de daño (siendo estos daños de tipo físico, psíquico o económico).

\subsubsection{Los sujetos de la relación paternalista}

Tomando como criterio los sujetos de la relación paternalista, podríamos diferenciar algunos tipos principales de paternalismo: 1) paternalismo en la empresa ${ }^{15}$, 2) paternalismo estatal, 3) paternalismo entre Estados o entre

\footnotetext{
${ }^{13}$ Véase: Mill, John S.: Sobre la libertad, (trad. Pablo de Azcárate), ed. Alianza Editorial, Madrid, 1999, p. 162; Ten, C. L.: "Mill on Self-Regarding Actions”, en Spitz, David (ed.): Mill, John S.: On Liberty (A Norton Critical Edition), ed. Norton \& Company, Nueva York, 1975; y Feinberg, Joel: Harm to Self, ed. Oxford University Press, Nueva York, 1986, p. 22.

${ }^{14}$ Ernesto Garzón aclara que la idea de que "nadie puede dañarse voluntariamente”, expresada tradicionalmente por medio de la antigua máxima "volenti non fit injuria", puede interpretarse, como ya señaló Aristóteles, de dos maneras diferentes: o bien como que nadie puede agraviarse a sí mismo (violar su propio derecho), o bien como que nadie puede perjudicarse a sí mismo. Solamente este segundo sentido de la máxima, dice nuestro autor, es el relevante para el paternalismo jurídico. Véase: Garzón Valdés, Ernesto: “¿Es éticamente justificable el paternalismo jurídico?”, en Doxa 5(1988), pp. 155-173.

${ }^{15}$ El término "paternalismo” (cuyos primeros usos constatados se remontan al último tercio del siglo XIX, siendo originario de la lengua inglesa) se usó en lengua castellana a principios del siglo XX casi exclusivamente para referirse a este tipo de paternalismo. Es de destacar que, por ejemplo, en la Enciclopedia Universal Ilustrada de Espasa, publicada por primera vez en 1920, la única acepción que se incluye de "paternalismo” es, precisamente, la siguiente: “Régimen de relaciones entre el patrono y el obrero que, asimilándolas a las familiares, atribuye al patrono una especie de protección tutelar sobre sus obreros”. Véase: Voz "Paternalismo" en Enciclopedia Universal Ilustrada, ed. Espasa-Calpe, Madrid, 1966, t. 42. Los ejemplos históricos de paternalismo industrial más importantes son las llamadas ciudades-fábrica. Paradigmáticos son los casos de Pullman City en los Estados Unidos, la cité Mulhouse o Le Creusot en Francia, Le Grand Hornu en Bélgica, etc. En España cabe destacar el paternalismo practicado en las explotaciones mineras de Río Tinto en Huelva y en las empresas mineras asturianas como Hullera Española en Bustiello, Solvay en Lieres o Ensidesa en Avilés. Los patronos paternalistas iban mucho más allá del pago del salario y proveían a los obreros de economatos, viviendas, cajas de previsión, educación, servicios religiosos, pero siempre supeditado a la continuidad en la empresa y al buen rendimiento en el puesto de trabajo. Se discute si se trataba realmente de paternalismo o simplemente de una manera de disciplinar a la mano de obra (sacar al obrero de
} 
comunidades ${ }^{16}$ y 4) paternalismo médico. A cada uno de los anteriores tipos le correspondería la siguiente expresión equivalente: 1) “el patrón ejerce paternalismo sobre el empleado”, 2) "el Estado ejerce paternalismo sobre los ciudadanos”, 3) “el Estado A ejerce paternalismo sobre el Estado B”, y 4) "el médico ejerce paternalismo sobre el paciente y/o sus allegados”. Vale la pena mencionar que entre estas categorías de paternalismo se dan diferencias en cuanto a los medios de que preferentemente se vale la intervención y las finalidades específicas. Al paternalismo estatal, por ejemplo, se le suele adscribir como medio preferente la coacción y como finalidad la más genérica del bienestar (de ahí la calificación de paternalista que se hace del Estado del Bienestar), mientras que al paternalismo médico se le suele adscribir como medio preferente el engaño o la ocultación de información (lo que explica que en este ámbito se denomine al consentimiento válido “consentimiento informado”) y como finalidad específica la salud del sujeto B (bienestar físico o psíquico) ${ }^{17}$.

Un caso especial, en relación con los sujetos del paternalismo, sería el denominado “auto-paternalismo”, en el cual el sujeto A ejerce paternalismo sobre sí mismo o sobre B pero con su consentimiento o a su requerimiento. Se trata de un caso de particular relevancia para la discusión del problema

la taberna era una obsesión de la época) y asegurar su reproducción. A mi juicio, sin embargo, en círculos de lo que podríamos llamar catolicismo social se predicaba y practicaba un paternalismo bastante sincero (aunque no del todo, porque con la filantropía se mezclaba el miedo al movimiento obrero). Sobre el paternalismo industrial en España, véase: Sierra Álvarez, José, El obrero soñado. Ensayo sobre el paternalismo industrial (Asturias, 1860-1917), ed. Siglo XXI, Madrid, 1990; Babiano Mora, J.: Paternalismo industrial y disciplina fabril en España, 1938-1958, ed. CES, Madrid, 1998.

${ }^{16}$ Véase: Garzón Valdés, Ernesto: “Intervencionismo y paternalismo”, en Garzón Valdés, Ernesto: Derecho, ética y política, ed. CEC, Madrid, 1993, pp.379-399. Un caso de paternalismo generalizado que recurrentemente encuentra defensores es el que John Stuart Mill denominaba “despotismo benevolente" con los "bárbaros”. Pero no porque haya pueblos "bárbaros”, sino porque el contacto entre sociedades de diferente nivel de desarrollo puede "barbarizar" a los pueblos menos desarrollados. Es absurdo pensar que una comunidad indígena amazónica aislada está constituida mayoritariamente por individuos incapaces, porque la propia subsistencia de la comunidad muestra que no es así. No obstante, si la pequeña comunidad indígena entra en contacto con una sociedad industrial, la modificación radical de sus circunstancias sociales puede convertir a todos, o a la mayoría, en incapaces. De ahí que la benevolencia puede aconsejar tanto el dejarlos tranquilos como el tratarlos paternalistamente una vez "descubiertos”.

${ }^{17}$ A estos tipos principales se les podría añadir quizá el paternalismo ejercido por los seres humanos con los animales. Jesús Mosterín y Jorge Riechmann han sostenido en su obra Animales y ciudadanos (ed. Talasa, Madrid, 1995) que si se quiere beneficiar a los animales esto debe hacerse por medio del paternalismo, puesto que "nuestras acciones con respecto a los animales nunca podrán contar con el consentimiento de estos” (op. cit., p. 191). Para un estudio detallado sobre los problemas conceptuales y éticos de los derechos de los animales: véase, De Lora, Pablo: Justicia para los animales. La ética más allá de la humanidad, ed. Alianza, Madrid, 2003. 
del paternalismo en el contexto de la democracia y, por ello, me detendré, aunque brevemente, en su análisis.

Cuando se trata de aclarar el concepto de auto-paternalismo, se suele acudir al conocido relato homérico de Ulises y las Sirenas; otros ejemplos de “auto-paternalismo” menos elegantes pero más reales serían el caso del jugador que pide que se le prohíba la entrada al casino, el estudiante perezoso que se matricula en una academia para que le obliguen a estudiar o el que acuerda con un amigo que no le deje conducir si ha bebido demasiado.

En el relato homérico, quien se ata a sí mismo, Ulises, es un individuo, pero en la discusión sobre el concepto de auto-paternalismo con frecuencia se maneja una versión política del “contrato Ulises”, en la que es la sociedad quien busca atarse a sí misma con las cuerdas de la intervención estatal, por lo que es conveniente distinguir al hablar de “auto-paternalismo” si el sujeto $\mathrm{B}$ es un individuo o una comunidad.

Igualmente, me parece conveniente distinguir aquellos supuestos en los que el mecanismo elegido para “atarse a sí mismo” requiere de las acciones de otros, de aquellos supuestos en los que el sujeto B pone en marcha algún mecanismo que no requiere la acción de otros. Este mecanismo puede descansar sobre una relación causal o convencional. Este último sería el caso, por ejemplo, de una legislatura limitando sus propios poderes al establecer que ciertas normas no pueden ser derogadas o modificadas en el futuro. Como mecanismos de auto-restricción que descansan sobre relaciones causales tendríamos, por ejemplo, los siguientes: quien se inyecta una sustancia que le hará intolerable en el futuro el consumo de alcohol o nicotina, quien se encierra a estudiar en una casa de campo aislada para no perder el tiempo en distracciones o, incluso, quien no acude a espectáculos violentos para evitar

Modalidades del auto-paternalismo

\begin{tabular}{|c|c|c|c|}
\hline & & \multicolumn{2}{|c|}{ Mecanismo de auto-restricción } \\
\hline & & $\begin{array}{c}\text { Compromiso con un } \\
\text { agente (Contratos } \\
\text { Ulises) }\end{array}$ & $\begin{array}{c}\text { Otros mecanismos } \\
\text { (Auto-paternalismo } \\
\text { estricto) }\end{array}$ \\
\hline \multirow[b]{2}{*}{ Sujeto } & Individual & $\begin{array}{c}(\mathrm{I}) \\
\text { Ej: Acordar con un } \\
\text { amigo que no me } \\
\text { deje conducir si bebo } \\
\text { demasiado }\end{array}$ & $\begin{array}{l}\text { (II) } \\
\text { Ej: Inyectarse una } \\
\text { sustancia que reac- } \\
\text { ciona negativamente } \\
\text { con la nicotina }\end{array}$ \\
\hline & Político & $\begin{array}{c}\text { (III) } \\
\text { Ej: Una legislatura } \\
\text { democrática apro- } \\
\text { bando una ley que } \\
\text { sanciona no llevar el } \\
\text { cinturón de seguridad } \\
\text { en los coches }\end{array}$ & $\begin{array}{l}\text { (IV) } \\
\text { Ej: Una asamblea } \\
\text { constituyente hacien- } \\
\text { do inmodificables } \\
\text { ciertas disposiciones } \\
\text { constitucionales }\end{array}$ \\
\hline
\end{tabular}


tener una preferencia por estos. Igualmente, cabría distinguir si el mecanismo imposibilita o sólo dificulta el uso de ciertas opciones.

Propongo denominar auto-paternalismo del tipo "contrato Ulises" cuando el mecanismo de auto-restricción consiste en acudir a otros individuos para que actúen paternalistamente y auto-paternalismo estricto cuando el propio sujeto $B$ pone en marcha algún otro mecanismo.

De estas cuatro modalidades de auto-paternalismo, me parece importante destacar lo siguiente:

(I) El tipo I, contratos Ulises en su versión individual, ha sido considerado por algunos autores como no paternalismo, generalmente porque se considera que la acción supuestamente paternalista de A consiste en seguir las instrucciones anteriores de $\mathrm{B}^{18}$. Estos autores asimilarían los contratos Ulises al contrato de mandato, en el que el mandatario actúa de acuerdo con las disposiciones del mandante. Ahora bien, el "contrato Ulises” muestra una importante peculiaridad frente al contrato de mandato, a saber, la renuncia al derecho de revocación por parte del sujeto B (en previsión de un futuro cambio de preferencias que puede suponerle graves perjuicios). Llegado el momento, B se opondrá a la acción de A y éste deberá, si quiere cumplir con las disposiciones previas de $\mathrm{B}$, ejercer el poder, a veces la fuerza, sobre B. En algunos de estos casos puede ser inadecuado describir la acción de A como paternalista si la intención de A es únicamente seguir las instrucciones de $\mathrm{B}$, pero en otros la intención de A será evitar daños a B y el consentimiento anterior de B será visto por A como una garantía de que su acción está justificada.

(II) El caso II, auto-paternalismo estricto individual, se aleja más del núcleo de claridad del concepto de paternalismo porque, aparentemente, viola el presupuesto del que hemos partido según el cual el paternalismo consiste en una relación entre dos sujetos. Bien pudiera decirse que en estos

\footnotetext{
${ }^{18}$ Esta parece ser la posición de Geral Dworkin, quien señala que en los “contratos” Ulises "la medida que debe ser impuesta es específicamente demandada por la parte afectada” y que "tal no es el caso de las medidas paternalistas de las que hemos estado hablando" (aunque no queda muy claro si sería un tipo de medidas paternalistas diferente o no sería paternalismo en absoluto).Véase: Dworkin, Gerald: “Paternalism”, en Sartorius, Rolf: Paternalism, cit., p. 29. Bernard Gert y Charles M. Culver son más claros al afirmar que cuando se cuenta con el consentimiento anterior del sujeto B, no se trata de paternalismo. Véase: Gert, Bernard y Charles M. Culver: "Paternalistic Behavior”, cit. Manuel Atienza comparte esta última posición, si bien deja abierta la cuestión de si, en los contratos Ulises, puede afirmarse que existe consentimiento a la acción "paternalista”. Véase: Atienza, Manuel: “Discutamos sobre paternalismo”, Doxa 5(1988), p. 209. Por el contrario, decididamente a favor de considerar estos supuestos como genuino paternalismo están Ernesto Garzón y Douglas N. Husak, quien afirma: "no plantea problemas conceptuales la pretensión de que se puede tratar paternalistamente a uno mismo". Véase: Husak, Douglas N.: "Paternalism and Autonomy", Philosophy \& Public Affairs 10 (1980), nº 1, p. 43.
} 
supuestos es donde el auto-paternalismo es verdaderamente auto-referente pero menos paternalismo, mientras que en el supuesto en el que B requiere a otra persona para que "lo ate" es más paternalismo pero menos auto-referente. En todo caso, la teoría de la racionalidad subyacente a estas auto-restricciones individuales es de gran importancia para el tema del paternalismo, en la medida en que puede contribuir a aclarar la racionalidad y, en última instancia, la justificación de las restricciones paternalistas. El principio básico de que disponer de menos opciones puede ser mejor, en ocasiones, que disponer de más opciones estaría detrás de la justificación de todas las prácticas paternalistas ${ }^{19}$.

(III) El tipo III sería el de, por ejemplo, las leyes emanadas de una legislatura democrática que impiden o dificultan a los ciudadanos la realización de actos que les suponen un daño o el aumento del riesgo de daño. Algunos autores han sostenido que estas leyes no son paternalistas. El argumento sería que si la existencia de la ley "se debe" 20 a las preferencias de los destinatarios o, más específicamente, a sus "preferencias sobre preferencias"21 no podemos hablar de paternalismo. Al igual que ocurriría en la versión individual de los contratos Ulises, los representantes políticos se limitarían en estos casos a seguir las directrices de los representados. A mi juicio, sin embargo, ni la práctica ni la teoría de la representación política en democracia apoyan este argumento. Con mucha frecuencia, las normativas paternalistas, pensemos por ejemplo en la obligación de llevar el cinturón de seguridad, se dictan contra las preferencias de los destinatarios, que no quieren que se les imponga la alternativa de llevar el cinturón de seguridad o correr el riesgo de ser sancionados, y se orientan a producir con el tiempo, ex post acto de promulgación, una modificación de las preferencias, de manera que los ciudadanos ya se ponen el cinturón por propia voluntad. El éxito de la legislación paternalista residiría en contribuir a la eliminación de preferencias irracionales y dañinas en los ciudadanos. No habría que confundir, por otro lado, la aceptación general o aquiescencia a un esquema general de gobierno en el que las interferencias paternalistas son permisibles, a una autorización o consentimiento por parte de los destinatarios a las concretas interferencias paternalistas.

${ }^{19}$ Sobre la teoría de las auto-restricciones, véase: Elster, Jon: Ulises desatado (Estudios sobre racionalidad, precompromiso y restricciones), ed. Gedisa, Barcelona, 2002.

${ }^{20}$ Véase: Elster, Jon: Ulises y las Sirenas. Estudios sobre racionalidad e irracionalidad, cit., pp. 144 y 145.

${ }^{21}$ Véase: Sunstein, Cass R.: “Legal Interference with Private Preferences”, en The University of Chicago Law Review, 53(1986), pp. 1140-41. 
(IV) El tipo IV correspondería, por ejemplo, a la auto-restricción que una legislatura puede imponerse a sí misma o, en el paradigma constitucionalista, a la rigidez constitucional (auto-paternalismo estricto político). Aquí, aparentemente, la aprobación de una norma por la cual ciertas reglas constitucionales son inmodificables hace imposible al propio constituyente cambiar esas reglas y respetar, a la vez, el Derecho. Francisco Laporta ha señalado que estos supuestos no serían de auto-paternalismo (más fácil de justificar) sino de paternalismo estricto, porque "quienes ordenan la vinculación no son generalmente los que la van a sufrir (...) se trata de individuos distintos o de generaciones distintas”22. Además, se trataría, según este mismo autor, de un paternalismo injustificable al considerar a las "mayorías democráticas del futuro" como perturbadas o dominadas por las pasiones, cuando lo que, en realidad está siendo protegido es, muchas veces, "lo pasional e interesado de los constituyentes que se blinda frente a la racionalidad de las futuras generaciones democráticas”23. Igualmente, Jon Elster que inicialmente consideró que las constituciones son mecanismos de pre-compromiso “elaboradas por el cuerpo político con el fin de protegerse a sí mismo contra su previsible tendencia a tomar decisiones imprudentes”24, recientemente ha sostenido que, con mayor frecuencia (aunque no exclusivamente), las constituciones son mecanismos por los que unos tratan de atar a los otros. A mi juicio, las consideraciones de estos autores me parecen aceptables, sin embargo, creo que habría algunos supuestos que caerían en esta categoría de auto-paternalismo estricto político: por ejemplo, Jon Elster señala que “cuando el Parlamento Constituyente húngaro, en los años 1989-1990, votó a favor de la creación de un Tribunal Constitucional con atribuciones muy amplias, que le conferían la capacidad de revocar las decisiones emanadas del Parlamento, eso constituyó un acto explícito de auto-limitación”25.

\subsection{El concepto de paternalismo jurídico}

1.3.1. Una plausible definición de paternalismo jurídico

Si el paternalismo en general consiste en el ejercicio de un poder, el paternalismo jurídico consistirá en el ejercicio de un poder jurídico. De manera que la definición de paternalismo jurídico sería la siguiente:

A ejerce paternalismo jurídico sobre B si y sólo si:

1) A ejerce un poder jurídico sobre $B$,

\footnotetext{
${ }^{22}$ Laporta, Francisco J.: “El ámbito de la Constitución”, en Doxa 24 (2001), p. 464.

${ }^{23}$ Ibídem.

${ }^{24}$ Elster, Jon: Ulises desatado, cit., p. 111.

${ }^{25}$ Elster, Jon: Ulises desatado, cit., p. 113.
} 
2) con la finalidad de evitar que B lleve a cabo acciones u omisiones que le dañan a sí mismo y/o le suponen un incremento del riesgo de daño (siendo estos daños de tipo físico, psíquico o económico).

Los actos jurídicos se caracterizan por haber sido realizados conforme a normas jurídicas que confieren poderes. Los poderes jurídicos se suelen dividir en poderes públicos (generalmente, llamados “competencias”) y privados (generalmente, llamados “capacidades”). Ambas, competencias y capacidades, son el ejercicio de poderes, pero mientras que se es “capaz para modificar la propia situación jurídica; en cambio, se es competente para modificar la de otras personas”26. Las competencias se caracterizan porque el titular de las mismas puede intencionalmente modificar la situación jurídica de otro sin contar con la aceptación del mismo, mientras que las capacidades o bien agotan sus efectos en la persona que las ejecuta o bien extienden sus efectos a terceros voluntarios. El ejemplo clásico de ejercicio de una capacidad es el negocio jurídico (que puede ser visto como promesas recíprocas) y de una competencia puede serlo el acto administrativo. Tan sólo los poderes públicos que son competencias pueden ser descritos como el ejercicio de un poder (jurídico) de A (el titular del poder) sobre B (el sujeto jurídicamente al poder de A).

Siguiendo con esta última idea, cabría decir que el paternalismo jurídico consiste en el ejercicio de una competencia jurídica. Dado que en el paternalismo el objetivo de A es evitar que B lleve a cabo actos que le dañan a sí mismo, que le suponen un incremento de riesgo de daño, es plausible sostener que en el paternalismo jurídico el ejercicio por parte de A de su competencia sobre B debe limitar de alguna manera las opciones de B (al menos, limitará a B una opción de auto-infligirse un daño, de aumentar los riesgos de daños).

El análisis de W. N. Hohfeld sobre las diferentes posiciones jurídicas en una relación jurídica ${ }^{27}$ puede ser, parcialmente, de aplicación aquí, obteniendo la siguiente definición de paternalismo jurídico:

El agente A ejerce paternalismo jurídico sobre $B$ si y sólo si:

1) A, en el ejercicio de una competencia, sitúa a $B$ en una posición de deber, no derecho, sujeción o incapacidad (en este último caso, para modificar su propia situación jurídica),

${ }^{26}$ Nino, Carlos S.: Introducción al análisis del Derecho, ed. Ariel, Barcelona, 1996, p. 222.

${ }^{27}$ Véase: Hohfeld, W. N.: Fundamental Legal Conceptions as Applied in Judicial Reasoning, ed. Ashgate-Dortmouth, 2001. 
2) con la finalidad de evitar que B lleve a cabo acciones u omisiones que le dañan a sí mismo y/o le suponen un incremento del riesgo de daño (siendo estos daños de tipo físico, psíquico o económico) ${ }^{28}$.

Como ejemplo de paternalismo jurídico podría señalarse el derecho a la educación de los menores. Éste es un derecho que tienen todos los ciudadanos, pero cuando se trata de los menores suele caracterizarse el mismo como de paternalista; sin embargo, es fácil advertir que lo que lo hace paternalista es que, en realidad, se configura como un “derecho-deber”. Lo mismo ocurre con el derecho a la vida, que siempre que se entiende como paternalista es concebido como “derecho-deber”. Otros ejemplos de regulaciones jurídicas que pudieran calificarse de paternalistas serían los siguientes: el derecho a la asistencia letrada (de ejercicio obligatorio) ${ }^{29}$, la irrenunciabilidad del derecho a la información clínica por parte del paciente cuando está en grave peligro su salud ${ }^{30}$, el no derecho a la información clínica en caso de necesidad terapéutica ${ }^{31}$, la prohibición de las lesiones con el consentimiento de la víctima ${ }^{32}$, etc.

Esta propuesta de concepto de paternalismo jurídico presentaría, a mi juicio, las siguientes ventajas:

1) Además de los casos en los que el paternalismo consiste en el establecimiento de una prohibición u obligación, incluye los casos en los que se declara incompetente a una persona, se la sujeta a la tutela de otra o se establece que no tiene derecho a realizar ciertos actos (dejándola en una situación de libertad no protegida). Por ejemplo, la sujeción a tutela de un discapacitado mental, la sujeción a la patria-potestad de los menores, la incapacidad de los menores para disponer de sus bienes inmuebles, la anu-

\footnotetext{
${ }^{28}$ El paternalismo jurídico puede ser visto también como la “asunción de competencias por parte de A”. Podría decirse que el acto paternalista fundamental de un sistema jurídico constitucional sería la atribución al Parlamento de competencia para perseguir la finalidad (respetando ciertos límites) de evitar que los ciudadanos lleven a cabo acciones u omisiones que les dañan y/o les suponen un incremento del riesgo de daño (siendo estos daños de tipo físico, psíquico o económico). La atribución de esta competencia implica lógicamente la sujeción de los ciudadanos. Cuando el Parlamento crea un estatus de la minoridad en la que establece que los menores deben quedar sujetos a la patria potestad, la situación puede ser descrita como la de conferir una competencia a los padres en relación con sus hijos. Igualmente, cuando se establece un deber para los ciudadanos con fines paternalistas (por ejemplo, la prohibición de navegar sin chalecos salvavidas) se otorga competencia a las autoridades judiciales y/o administrativas para sancionar por el incumplimiento de ese deber.

${ }^{29}$ Véanse los artículos 118.4 y 788.1 de la Ley de Enjuiciamiento Criminal española

${ }^{30}$ Véase el artículo 9.1 de la Ley 41/2002, básica reguladora de la autonomía del paciente y de derechos y obligaciones en materia de información y documentación clínica.

${ }^{31}$ Véase el artículo 5.4 de la Ley 41/2002, básica reguladora de la autonomía del paciente y de derechos y obligaciones en materia de información y documentación clínica.

${ }^{32}$ Véase el artículo 155 del vigente Código Penal español.
} 
lación de las disposiciones generales en un contrato tipo no favorables a la parte “débil” del contrato, la imposibilidad (institucional) de constituir válidamente un contrato de esclavitud perpetua o un contrato válido de trabajo por debajo del salario mínimo, etc.

2) Igualmente, esta definición incluye los casos de paternalismo indirecto (o impuro, según la concepción de Gerald Dworkin) ${ }^{33}$, ya que la coacción que directamente se dirige contra un individuo indirectamente deja al sujeto B en una situación de no derecho: por ejemplo, la ilegalización de un comercio como el de las drogas (implique esta ilegalización una persecución penal o no) deja a los sujetos tratados paternalistamente, los consumidores, en una situación de no derecho: pueden tratar de obtener drogas en el mercado ilegal, pero el Estado puede, por su parte, hacer todo lo posible para impedirlo.

3) Al considerar el paternalismo jurídico como el ejercicio de un poder jurídico también se pone de manifiesto que el paternalismo se puede ejercer en diferentes etapas. En primer lugar, tendríamos un poder constituyente (si se trata de un sistema constitucional) que puede ejercer el paternalismo, por ejemplo, configurando el derecho constitucional a la asistencia letrada como un derecho-deber. En segundo lugar, tendríamos un poder legislativo que puede, siguiendo con el mismo ejemplo, establecer en las leyes procesales la obligación de la asistencia letrada. En tercer lugar, encontraríamos un juez que declara que cierto acusado no tiene derecho a defenderse a sí mismo sin contar con la asistencia letrada. Por último, tendríamos, en algunos casos, un funcionario público que ejecuta las disposiciones del juez ${ }^{34}$.

4) Se aclara la conexión entre la discusión sobre el paternalismo jurídico y la discusión de la filosofía política sobre el paternalismo y las formas de gobierno. Fuera de la anterior escala, o por encima de ella, habría un nivel de paternalismo que se refiere a las formas de gobierno: en particular, la contraposición entre democracia y despotismo benevolente. Un régimen de despotismo benevolente está configurado totalmente sobre la idea de paternalismo, mientras que la democracia parece fundarse en su negación. Sin embargo, en la democracia, la forma de gobierno caracterizada por la

\footnotetext{
${ }^{33}$ El paternalismo indirecto (Joel Feinberg) o impuro (Gerald Dworkin) supone que para evitar daños a B se ejerce coacción sobre un tercero C: por ejemplo, cuando para evitar los daños derivados del consumo de drogas, se sanciona al traficante-vendedor y no al consumidorcomprador. Véase: Feinberg, Joel, Harm to Self, cit., p. 9; y Dworkin, Gerald: "Paternalism”, en Sartorius, Rolf: Paternalism, cit., p. 22.

${ }^{34}$ Estos últimos actos, que son de pura aplicación del Derecho, difícilmente pueden ser vistos como actos jurídicos y, de acuerdo con mi propuesta, como actos de paternalismo jurídico. Sin embargo, lo más razonable me parece que es considerarlos una categoría sui generis de paternalismo jurídico.
} 
autonomía, se dan, a su vez, formas de Derecho autónomas y heterónomas. De ahí que, en cierto sentido, quepa decir que el paternalismo es incompatible con la democracia, si nos situamos en el nivel de las formas de gobierno, y, al mismo tiempo, que dentro de la democracia se pueden dar ejercicios paternalistas del poder. Las normas emanadas de una legislatura democrática pueden ser vistas como ejercicio de la autonomía del pueblo (que actuaría por medio de representantes), pero en la medida en que sus disposiciones se apliquen a los destinatarios de las mismas sin requerir para ello su consentimiento individual son heterónomas (suponen el ejercicio de una competencia) y, por tanto, susceptibles de ser paternalistas ${ }^{35}$.

5) Se aclara, finalmente, la relación entre el paternalismo jurídico y la coacción. En un sentido amplio, sería cierto que el paternalismo jurídico siempre es coactivo, puesto que es el resultado del ejercicio de competencias que modifican la situación jurídica de un individuo lo quiera éste o no. Competencias que, además, están respaldas en última instancia por la fuerza. En un sentido estricto, sin embargo, el paternalismo jurídico sólo sería coactivo cuando recurre al establecimiento de sanciones como instrumento principal de una política paternalista.

\subsubsection{Paternalismo jurídico y paternalismo estatal}

El paternalismo estatal puede ser sencillamente caracterizado sustituyendo "A” por "órgano del Estado" en el enunciado "A ejerce paternalismo sobre B”. Debe considerarse paternalismo estatal a cualquier acción paternalista llevada a cabo por un órgano del Estado, pero sólo se tratará de

\footnotetext{
${ }^{35}$ En el siguiente párrafo de Hans Kelsen creo que se encuentra una más clara explicación de esta misma idea: "En el punto central de los problemas de una dinámica jurídica -dice Hans Kelsen- se encuentra la pregunta por los diferentes métodos de producción de derecho, o por las formas del derecho. Si se pone la mira en aquellas normas jurídicas que configuran la parte principal de un orden jurídico, a saber: las que enlazan una sanción como acto coactivo a determinada conducta humana, y si se reconoce que un hombre se encuentra jurídicamente obligado a una determinada conducta en cuanto la conducta contraria ha sido convertida en condición de una sanción, pueden distinguirse dos tipos de normas jurídicas que estatuyen tales obligaciones jurídicas: aquellas en cuya producción el hombre obligado participa, y aquellas que aparecen sin su participación. El principio que se encuentra en la base de esta distinción, es el de la libertad en el sentido de autodeterminación. La cuestión decisiva, desde el punto de vista del hombre sujeto a normas, es si la obligación se produce con su voluntad, o sin ella y eventualmente, incluso contra su voluntad. Se trata de la distinción que habitualmente se designa como la oposición entre autonomía y heteronomía, y que la teoría del derecho suele establecer en lo esencial en el terreno de los derechos estatales. Aquí aparece como una diferencia entre democracia y autocracia, o entre República y monarquía, permitiendo la visión corriente de las formas del estado. Sólo que aquello que se concibe como la forma del estado no es más que un caso especial de la forma del derecho en general”, en Kelsen, Hans: Teoría Pura del Derecho, ed. Porrúa, México, 1993, p. 285.
} 
paternalismo jurídico estatal cuando el medio directo empleado sean las normas jurídicas.

Dentro del conjunto de las acciones del Estado cabe distinguir aquellas en las que sus objetivos se logran directamente por medio de la modificación de la posición jurídica de los individuos, de aquellas en las que esta modificación sólo tiene un papel secundario y el medio empleado para alcanzar tales objetivos tiene otra naturaleza. La acción del Estado siempre tiene un aspecto jurídico. La construcción de una autopista estatal requiere de un procedimiento de derecho administrativo y hasta el más mínimo detalle de la planificación y ejecución de las obras queda reflejado en un documento. Sin embargo, el Derecho tiene un aspecto secundario en la construcción de la autopista: ésta se realizará si se dispone de los recursos humanos y del dinero suficientes. En otros casos, las normas jurídicas son el medio directo de que se vale el Estado para conseguir sus fines: por ejemplo, cuando dicta una norma que prohíbe conducir sin el cinturón de seguridad. Podemos suponer que un Estado preocupado por el elevado número de accidentes, además de construir mejores carreteras (lo que requiere recursos humanos y dinero) y de prohibir ciertos comportamientos peligrosos (por medio de normas jurídicas), decidirá mantener campañas periódicas de concienciación sobre los riesgos de la conducción; aquí parece que el medio directo de que se vale el Estado es la persuasión. En resumen, la acción estatal se vale principalmente de cuatro tipos de medios: dinero, recursos humanos, normas jurídicas y persuasión ${ }^{36}$.

Habría, en consecuencia, supuestos de paternalismo estatal no jurídico. Veamos algunos de ellos. En primer lugar, tendríamos aquellos supuestos en los que el Estado establece incentivos económicos con fines paternalistas ${ }^{37}$.

\footnotetext{
${ }^{36}$ La clasificación está recogida de Pallarés, Francesc: “El sistema político en acción”, en Revista de Estudios Políticos, 62(1988), p. 144; el cual, a su vez, sigue el planteamiento expuesto en Peters, B. G.: American Public Policy, Franklin Wats Pubs., Nueva York, 1982.

${ }^{37}$ También sería paternalista, de acuerdo con la definición de paternalismo presentada, el establecimiento de incentivos económicos orientados a modificar la estructura de preferencias del sujeto B con la finalidad de evitar que B se dañe a sí mismo (los incentivos serían una forma de ejercer el poder). Un ejemplo de este tipo de paternalismo, poco frecuente, serían los incentivos para la contratación de planes de pensiones, siempre que entendamos que una consecuencia de la medida, previsible y deseada por el legislador, es la disminución de las personas que, por imprevisión, no tendrán recursos suficientes para disfrutar de una vejez digna. Hay que advertir la importancia que tiene la segunda condición de la definición de paternalismo para distinguir estos casos de las meras intervenciones benevolentes. Si como es de desear el Estado ejerce su poder siempre para beneficiar a los ciudadanos, podría argumentarse que, de acuerdo con mi definición, casi todas las intervenciones estatales son paternalistas. Sin embargo, esto no es así porque la finalidad del paternalismo no es simplemente evitar daños a los ciudadanos, sino más estrictamente evitar que se dañen a sí mismos. La concesión de una subvención para, por ejemplo, los agricultores no es necesariamente paternalista, pero lo será si esa subvención
} 
Otro supuesto de este tipo de paternalismo serían los gravámenes orientados a que los ciudadanos abandonen hábitos de vida no saludables: por ejemplo, elevando el precio del tabaco. En tercer lugar, tendríamos un conjunto de casos en los que el medio empleado por el Estado para ejercer el paternalismo sería la persuasión. Aquí se incluiría un abanico de ejemplos que van desde lo más inocuo, como la publicidad orientada específicamente a que los ciudadanos se comporten de cierta manera, hasta lo más peligroso, como sería la propagación de informaciones falsas para proteger a los ciudadanos de su propias acciones auto-dañosas. Dentro de este último conjunto de casos, merecería la pena destacar aquellos en los que el engaño adopta la forma de una manipulación sutil de la información. Me refiero a los supuestos de información sesgada o manipulada. Daniel Wikler sostiene, refiriéndose a las políticas públicas orientadas a la adopción de hábitos de vida saludables, que el instrumento de la información puede ser hábilmente utilizado, de manera que más allá de proveer información al objeto de adoptar una decisión racional, se producen fenómenos de manipulación ${ }^{38}$. En España, por ejemplo, la política pública de prevención del consumo de drogas no sólo se basa en la coacción penal, sino que utiliza profusamente el medio de la persuasión, a través de campañas publicitarias en los “mass media”. Estas campañas se encargan a agencias de publicidad, cuya especialidad no es presentar los mejores argumentos sino los más persuasivos. Además, estas campañas ni siquiera son centralmente retóricas; no se basan en los argumentos más que en la imagen y el sonido. Están dirigidas, en definitiva, a generar una respuesta hostil al consumo de drogas, una especie de reflejo condicionado a “decir NO” (que fue el eslogan de una de ellas).

En cuarto y último lugar, tendríamos como un tipo de paternalismo estatal no jurídico, aunque por razones diferentes a los anteriores; el caso del paternalismo entre Estados. Si el paternalismo se ejerce por un Estado sobre otro, éste adoptará normalmente la forma de las “injerencias coactivas” a las que se refería Ernesto Garzón ${ }^{39}$, entre las cuales la invasión armada sería la más significativa. No obstante, el proceso, lento y difícil, de la juridificación

está orientada a disuadir a los productores de hacer algo que les perjudica. Imaginemos que un sector agrícola no es económicamente viable y que, sin embargo, por costumbre, miedo o desconfianza los agricultores se resisten a cambiar a otros cultivos más provechosos; el Estado puede prohibir esa producción, desincentivarla o, incluso, incentivar otros cultivos. Este tipo de políticas previsiblemente combinan diversos objetivos (entre ellos, sin duda, mejorar la economía nacional), pero en la medida en que una de las consecuencias previsible y deseable de la misma es evitar que los agricultores se dañen a sí mismos también es paternalista.

${ }^{38}$ Wikler, Daniel: "Persuasion and Coercion for Health”, en Sartorius, Rolf: Paternalism, cit. p. 53.

${ }^{39}$ Véase: Garzón Valdés, Ernesto: “Intervencionismo y paternalismo”, en Garzón Valdés, Ernesto: Derecho, ética y política, cit. 
de la vida internacional favorece que aparezcan supuestos de paternalismo jurídico-internacional entre Estados y agentes paternalistas internacionales.

Si no todo paternalismo estatal es paternalismo jurídico, tampoco todo paternalismo jurídico es paternalismo estatal. En principio, pareciera que si el paternalismo jurídico consiste en el ejercicio de competencias jurídicas y éstas son siempre ejercidas por órganos del Estado, entonces el paternalismo jurídico debe ser siempre paternalismo estatal. Sin embargo, es evidente que hay sujetos que ejercen competencias sin ser órganos del Estado o, al menos, sin serlo de la misma manera de lo que, en general, entendemos por órganos del Estado. Pensemos, por ejemplo, en el caso del médico o de los sujetos que ostentan la patria-potestad.

De acuerdo con la Ley de Autonomía del Paciente española ${ }^{40}$, si el médico responsable de la asistencia juzga que el paciente no es capaz de tomar sus propias decisiones, entonces el consentimiento informado debe otorgarlo la familia (art. 9.3). Podría decirse que al médico se le confiere el poder de determinar, a los efectos de prestar consentimiento al tratamiento, la capacidad del paciente y, por tanto, el médico ejercería una competencia similar a la del juez que establece, por ejemplo, que una persona es incompetente para disponer de sus bienes. Igualmente, la patria potestad supondría el ejercicio de competencias de representación (sin necesidad de que el hijo sometido a la misma consienta) e, incluso, cierto poder sancionatorio (el llamado derecho de corrección).

No creo que se gane mucho negando que en estos casos se trata del ejercicio de competencias y tampoco afirmando que el médico o los padres son órganos del Estado. Quizás una solución sea acudir a un género superior, el de la producción de resultados normativos por métodos autocráticos (que no requieren el consentimiento del afectado), y distinguir dentro de él el ejercicio de competencias por parte del Estado y otros ejercicios de poder entre particulares que, en algunos supuestos, se caracterizarían por enmarcarse en relaciones paternalistas. Éste sería el caso de las relaciones de tutela y curatela, de la propia relación paterno-filial, de la relación marital de acuerdo con la regulación pre-constitucional española, de algunos aspectos de la relación médico paciente, etc.

\subsection{Otras distinciones relevantes}

Para terminar con el apartado conceptual y pasar al estudio de los problemas de justificación quisiera referirme sumariamente a algunas distinciones relevantes.

${ }^{40}$ Ley 41/2002, básica reguladora de la autonomía del paciente y de derechos y obligaciones en materia de información y documentación clínica. 
En primer lugar, principalmente en relación con el paternalismo jurídico, conviene distinguir entre aquellas disposiciones que son puramente paternalistas, es decir, cuya única finalidad es evitar daños auto-infligidos de tipo físico, psíquico y/o económico, de aquellas que tienen otras finalidades junto a la paternalista y que podríamos denominar de "paternalismo mixto".

En segundo lugar, conviene recordar la distinción entre casos de paternalismo directo, es decir, aquellos en los que se ejerce el poder directamente sobre el sujeto a quien se trata de evitar daños, y casos de paternalismo indirecto, es decir, aquellos en los que directamente se ejerce el poder sobre un sujeto e indirectamente sobre quien es tratado paternalistamente: por ejemplo, cuando para evitar los daños derivados del consumo de drogas se sanciona a los vendedores de drogas.

En tercer lugar, es conveniente distinguir entre una acción paternalista y una justificación paternalista. La justificación paternalista se orientaría a presentar el ejercicio del poder sobre un sujeto como aceptable apelando a dos razones: 1) la acción evita daños importantes y 2) es necesaria por cuanto el sujeto sobre el que se ejerce el poder no está en condiciones de cuidar de sus propios intereses.

En cuarto y último lugar, conviene hace referencia a la importante distinción entre paternalismo fuerte (o duro) y paternalismo débil (o blando). Joel Feinberg ha propuesto, en relación con la justificación de la coacción penal, distinguir entre el paternalismo fuerte, que “aceptará como una razón para la legislación penal que es necesaria para proteger a adultos competentes, contra su voluntad, de las consecuencias dañosas de sus elecciones y empresas, aunque sean plenamente voluntarias", del "paternalismo débil, que "sostiene que el Estado tiene derecho a prevenir la conducta dañosa auto-referente (en esta medida parece "paternalista”) si y solo si esa conducta es sustancialmente no voluntaria, o cuando una intervención temporal sea necesaria para establecer si es voluntaria o no" ${ }^{41}$. Se trata de una distinción que suele entenderse de dos maneras: como una distinción conceptual entre el genuino paternalismo (paternalismo fuerte) y el falso o aparente paternalismo (paternalismo débil), o como una distinción entre formas de paternalismo plausiblemente justificado (paternalismo débil) e injustificado (paternalismo fuerte). A mi juicio, esta segunda opción es la más correcta.

El término "paternalismo" fue introducido por Hart en el ámbito de la filosofía moral y jurídica como un argumento contra el moralismo jurídico defendido por Lord Devlin. De acuerdo con este último, la tradicional irrelevancia otorgada por el Derecho penal al consentimiento de la víctima (por ejemplo, el los delitos de lesiones u homicidio) mostraba un fundamento

${ }^{41}$ Véase: Feinberg, Joel: Harm to Self, cit., p. 12. 
moralista en la legislación ${ }^{42}$. Hart sostuvo, por el contrario que "las normas que excluyen el consentimiento de la víctima como una eximente contra las acusaciones de asesinato o agresión pueden ser perfectamente explicadas como un caso de paternalismo, dirigido a proteger a los individuos de sí mismos" "43. Para Hart la justificación de tales interferencias paternalistas había que buscarla en "una conciencia creciente de un gran conjunto de factores que disminuyen la significación que hay que atribuir a una elección o consentimiento aparentemente libre" ${ }^{44}$. Esta "conciencia” a la que alude Hart constituye, en mi opinión, el núcleo de la idea de paternalismo: quien actúa paternalistamente presupone algún tipo de déficit en el sujeto sobre el que actúa. De ahí que la noción de "paternalismo duro" nos remita o bien a otras figuras en las que no se trata tanto de proteger al individuo como de perseguir algunas formas de explotación inmorales, salvaguardar el orden público, etc. ${ }^{45}$, o bien a casos de paternalismo ejercido sobre el presupuesto erróneo de la existencia de algún déficit en los destinatarios de la medida. Pero estas consideraciones ya están demandando pasar al siguiente apartado sobre la justificación del paternalismo.

\section{La justificación del paternalismo}

Entendido el paternalismo según mi definición, ninguna doctrina política completa ha rechazado frontalmente el paternalismo porque todas lo han admitido en algunos casos. Al menos, todas las doctrinas han admitido la justificación del paternalismo en relación con los niños. Este paternalismo universalmente aceptado, el paternalismo con respecto a los niños, parece constituir el punto de partida adecuado para tratar de la justificación del pa-

\footnotetext{
42 Devlin, Patrick: The Enforcement of Morals, ed. Oxford University Press, 1968, p. 6. La concepción del moralismo jurídico que mejor explica la posición de Patrick Devlin es la que lo pone en relación con el denominado comunitarismo, de manera que se trata de imponer coactivamente la moral de una sociedad, en la medida en que se entiende que cierto conjunto de creencias y valores tienen un carácter constitutivo de ese grupo social. Lo que parece estar en juego en los actos que atentan contra la moral social es, por tanto, la existencia de la sociedad misma. Sobre esta aproximación al concepto de moralismo jurídico, véase: Colomer, José Luis: “Libertad individual y límites del derecho”, en Díaz, Elías y José Luis Colomer (dirs.): Estado, justicia, derechos, Alianza Editorial, Madrid, 2002, pp. 183 y ss.

${ }^{43}$ Hart, H.L.A.: Law, Liberty and Morality, ed. Stanford University Press, 1963, p. 31.

${ }^{44}$ Hart, H.L.A.: Law, Liberty and Morality, cit., p. 32.

${ }^{45}$ Un ejemplo de este tipo de intervenciones sería el delito del art. 155 del Código penal español, de acuerdo con el cual "en los delitos de lesiones si ha mediado el consentimiento libre, espontánea y expresamente emitido del ofendido, se impondrá la pena inferior en uno o dos grados”. Se trataría, a mi juicio, de uno de esos delitos "contra la sociedad” (contra el “orden público” podría decirse) que trataría de sancionar la inmoralidad intrínseca del acto de producir lesiones a otro, con la única justificación (pretendida) por parte del agresor del consentimiento de la víctima.
} 
ternalismo y, de hecho, tanto en la tradición del pensamiento político (Aristóteles, Thomas Hobbes, John Locke) como en las más recientes aportaciones (Gerald Dworkin) ésa ha sido la estrategia argumentativa escogida.

La universalización de la aceptación del paternalismo en relación con los niños juega en dos direcciones: por un lado, parece implicar que los adultos en tanto que no son niños no deben ser tratados de la misma manera y, por otro lado, exige que si los adultos son iguales a los niños en algunos aspectos relevantes deben ser tratados de la misma manera.

La conciliación de estos dos aspectos del principio de igualdad formal se realiza a través de la construcción de una noción más general que la de minoridad y que incluiría a ésta: la noción de incapacidad Así, debemos decir que los niños pueden ser tratados paternalistamente no por el simple hecho de ser niños, sino porque esa propiedad conlleva, en la mayoría de los casos, otra: la de ser incapaces. El juicio moral más general es, por tanto, que puede estar justificado tratar paternalistamente a los incapaces, sean niños o adultos.

Uno de los elementos claves de la justificación del paternalismo es el del contexto en el que se lleva a cabo la interferencia paternalista. La distinción propuesta por Jack D. Douglas entre paternalismo cooperativo y conflicti$\mathrm{vo}^{46}$ me parece interesante entenderla como paternalismo en contextos (potencialmente) cooperativos y paternalismo en contextos (potencialmente) conflictivos. La familia sería el modelo del paternalismo cooperativo y el Estado el del paternalismo conflictivo. Habría dos diferencias relevantes entre estos contextos: la primera es sobre el mayor o menor grado de posibilidad de que el paternalismo sea genuino paternalismo (es decir, genuinamente benevolente) y la segunda sobre el mayor o menor grado de posibilidad de conocimiento de los intereses del sujeto tratado paternalistamente.

El paternalismo en el ámbito de la familia se caracterizaría por una alta probabilidad de que el agente A actúe movido exclusivamente por el bien de B y también por una alta probabilidad de que los intereses (subjetivos) de B sean conocidos por A. Por el contrario, en el ámbito estatal la probabilidad de que el Estado actúe movido exclusivamente por el bien del sujeto B puede ser muy baja y también se puede dudar de las posibilidades de

\footnotetext{
${ }^{46}$ Este autor define el "paternalismo cooperativo" como "cualquier forma de paternalismo (hacer el bien a otros en nombre de lo que "es bueno para ellos”) en la que aquellos que actúan paternalistamente están actuando sinceramente para ayudar a la otra persona a devenir más independientemente competente a largo plazo, y la otra persona cree sinceramente que éste es el caso"; y el "paternalismo conflictivo” como aquél que "no está orientado a la competencia independiente e igualdad a largo plazo del miembro subordinado de la relación”. Véase: Douglas, Jack D.: “Cooperative Paternalism versus Conflictual Paternalism”, en Sartorius, Rolf (ed): Paternalism, cit., 1987, pp. 171-200.
} 
este agente de conocer los intereses (subjetivos) de B. Estas observaciones generales fundamentan la postura que sostiene que el cuidado y educación de los menores debe estar en manos de sus progenitores y el Estado debe, tan sólo, supervisar y vigilar, de forma muy general, el cumplimiento de estos deberes.

En lo que sigue me referiré principalmente a la justificación del paternalismo en contextos conflictivos y, en particular, al paternalismo en la relación del Estado con sus ciudadanos. En éste ámbito, parece haber un acuerdo casi unánime sobre la importancia del principio de autonomía individual, que podría verse como un principio que a partir de una formulación muy general, “deben respetarse las decisiones privadas de los individuos”, establece una obligación prima facie de no interferencia. Sin embargo, también es plausible afirmar la validez de una principio de bienestar, de acuerdo con el cual el Estado debe velar por el bienestar de sus ciudadanos. El principio de paternalismo justificado sería un principio secundario ${ }^{47}$, que constituiría una especificación del alcance que se le ha de reconocer al principio de autonomía individual en relación con consideraciones de bienestar individual.

A mi juicio, dicho principio de paternalismo justificado podría enunciarse de la siguiente manera:

A ejerce paternalismo sobre $B$ por medio de $X$, de forma justificada si y sólo si:

1) $X$ es una medida idónea y necesaria, en el sentido de que evita que $B$ se dañe a sí mismo o incremente el riesgo de daños (siendo estos daños de tipo físico, psíquico o económico) y no hay una forma alternativa no paternalista y de costes razonables para evitar esos daños, $y$

2) la tendencia a la producción de esos daños o el incremento de riesgo de daños tiene su fuente en una situación de incapacidad básica del sujeto $B, y$

3) se puede presumir racionalmente que B prestaría su consentimiento tanto a la posibilidad general de ser tratado paternalistamente por A en ciertas ocasiones como al contenido concreto de $X$, si no estuviera en una situación de incapacidad básica.

A continuación, examinaré cada una de las condiciones de justificación propuestas.

${ }^{47}$ Una caracterización de los principios de la bioética como un conjunto de principios primarios y secundarios (en la que el paternalismo es un principio secundario al principio de autonomía) puede verse en Atienza, Manuel: “Juridificar la bioética”, en Rodolfo Vázquez (comp.): Bioética y derecho, Ed. FCE-Itam, México, 1999. 


\subsection{La idoneidad y la necesidad de la medida paternalista}

El juicio de idoneidad de una medida paternalista $\mathrm{x}$ se compone de dos partes: primero, la determinación de que algo es un daño para el sujeto B y, segundo, la determinación de que $\mathrm{x}$ es un medio adecuado para evitar ese daño.

En contextos cooperativos de paternalismo es donde más fácil parece fundamentar la primera parte del juicio de idoneidad. La cercanía entre los sujetos de la relación paternalista favorece que el agente A esté en condiciones de determinar con mayor fiabilidad qué constituye un daño para B. La determinación de que cierta conducta de $\mathrm{B}$ constituye un daño o el incremento de riesgo de daño para B no es un juicio particularmente difícil, en el sentido de que esa conducta daña algún interés de B. El problema reside en determinar si esa conducta daña a B y, además, ese daño no es compensado por la mayor protección o promoción de otro interés del individuo. Una persona puede, por ejemplo, preferir el dolor a una prolongación del tratamiento hospitalario. Si A trata de evitar el dolor a costa de alargar su hospitalización, podría decirse que, ciertamente, A ha evitado un daño B, pero no que le ha evitado un daño como resultado final (es decir, tomando en cuenta cómo son afectados otros intereses de B). Por el contrario, conforme modificamos la situación hacia contextos conflictivos de paternalismo la primera parte del juicio de idoneidad deviene más complicada.

La segunda parte del juicio de idoneidad así como el juicio de necesidad (aquel que establece que no existe una medida alternativa que logre el mismo objetivo pero a un menor coste) son, igualmente, más sencillas en contextos cooperativos que en contextos conflictivos de paternalismo. No obstante, la forma personal en que se ejerce el paternalismo en contextos cooperativos (el padre en la familia, el médico en su unidad, etc.) puede derivar con frecuencia en un autoritarismo (aunque benevolente) que sería una desviación del paternalismo justificado basado en el incumplimiento de la condición de necesidad de la medida. En contextos conflictivos y, en particular, en relación con el paternalismo estatal la corrección de la segunda parte de los juicios de idoneidad y de los juicios de necesidad depende de su conformidad con las teorías sobre la legislación y las políticas públicas. Algunas de las políticas orientadas a evitar los daños derivados del consumo de drogas, por ejemplo, están hace tiempo en discusión por las dudas que suscitan al respecto de su idoneidad y necesidad; en particular, los castigos penales no parecen ni idóneos ni necesarios para el paternalismo.

En todo caso, me parece importante resaltar que el argumento de la inutilidad no es aplicable en abstracto contra las medidas paternalistas, aún cuando se trate de paternalismo estatal. De acuerdo con este argumento, el paternalismo estatal sería rechazable en general porque necesariamente es 
contraproducente, es decir, tal y como sostiene John S. Mill, porque el individuo siempre sale perdiendo con la interferencia paternalista. A mi juicio, sin embargo, en la medida en que la interferencia paternalista se limite a la protección de los intereses más básicos de los individuos, sobre el presupuesto de que si estos intereses están amenazados es porque los individuos se hallan en una posición de incapacidad básica, no hay razón para sostener el argumento de la inutilidad contra el paternalismo estatal en general. Por otro lado, como ha señalado Cass R. Sunstein, si la interferencia produce un cambio en las preferencias de los individuos no cabría aplicar este argumento de la inutilidad: por ejemplo, la imposición del cinturón de seguridad termina creando el hábito de ponerse el cinturón y disolviendo, por tanto, la oposición inicial ${ }^{48}$. La mayoría de las medidas paternalistas suelen pretender (y producir) este efecto de modificación de las preferencias mismas.

Sin embargo, el argumento de la inutilidad es de aplicación directa contra el perfeccionismo estatal. Con respecto a cuestiones morales, creencias religiosas o, en general, los aspectos más importantes del plan de vida del individuo habría un vínculo constitutivo entre convicción y valor. Éste sería el argumento principal de, por ejemplo, John Locke contra la imposición de las creencias religiosas (las creencias tienen valor si son asumidas por el individuo, si son impuestas ya no tienen valor) ${ }^{49} \mathrm{y}$, en nuestro tiempo, de Ronald Dworkin, quien distingue entre un paternalismo crítico coercitivo y un paternalismo volitivo ${ }^{50}$. Según este último autor, el paternalismo crítico coercitivo se caracterizaría porque el Estado intenta "mejorar la vida de los ciudadanos obligándoles a actuar de maneras que ellos piensan que empeoran su vida"51, a lo que añade que "una buena parte del paternalismo estatal no es de carácter crítico, sino volitivo: el Estado obliga a la gente a usar los cinturones de seguridad para evitarles un daño que supone que ellos mismos ya desean evitar”52, de ahí que este último paternalismo iría sólo contra la voluntad de los ciudadanos, mientras que el primero iría además contra su convicción.

El "paternalismo crítico coercitivo” no sería "paternalismo” de acuerdo con mi definición, se trataría de moralismo jurídico, y contra él se puede

${ }^{48}$ Véase: Sunstein, Cass R.: “Legal Interference with Private Preferences”, cit., pp. 11361138; y De Páramo Argüelles, Juan Ramón: Tolerancia y liberalismo, ed. Centro de Estudios Constitucionales, Madrid, 1993, p. 38.

${ }^{49}$ Véase: Locke, John: Carta sobre la tolerancia, ed. Tecnos, Madrid, 1985; y De Páramo Argüelles, Juan Ramón: Tolerancia y liberalismo, cit., pp. 31-35.

${ }^{50}$ Véase: Dworkin, Ronald: Ética privada e igualitarismo político, ed. Paidós, Barcelona, 1993, pp. 140-154.

${ }^{51}$ Dworkin, Ronald: Ética privada e igualitarismo político, cit., p. 143.

${ }^{52}$ Ibídem. 
esgrimir el argumento de la inutilidad de la siguiente manera: alguien puede pensar que, por ejemplo, la devoción religiosa es importante, “pero no puede pensar que la observancia religiosa involuntaria, orar a la sombra del potro de tortura, tiene valor ético alguno" ${ }^{\text {"33. }}$

\subsection{La incapacidad básica del sujeto tratado paternalistamente}

El aspecto más problemático de la justificación del paternalismo lo constituye, sin duda, la idea de incapacidad. Al respecto, en primer lugar, me parece útil seguir la propuesta de Ernesto Garzón y partir, por lo que respecta al paternalismo, de una concepción general de la incapacidad ${ }^{54}$, de manera que ésta no se entienda como una circunstancia entre otras que afecta a la voluntariedad de una decisión (la incapacidad en sentido estricto) ${ }^{55}$, sino que sería el concepto más general que da cuenta de una forma unitaria de todos los factores que pueden reducir la voluntariedad de un acto.

En segundo lugar, me parece importante distinguir, tal y como hacen Tom L. Beauchamp y James F. Childress, entre la función que cumple la noción de capacidad, su definición, los estándares de capacidad y las pruebas para establecer la capacidad. La función de los juicios de capacidad es distinguir entre las personas cuyas decisiones auto-referentes deben ser respetadas (capaces) y las personas cuyas decisiones pueden no ser respetadas (incapaces). Con respecto a la definición de capacidad, todos los autores coinciden en que la capacidad consiste en "la capacidad para desempeñar una determinada tarea” y Joel Feinberg ${ }^{56}$, Ernesto Garzón ${ }^{57}$, Bernard Gert y Charles M. Culver coincidirían en que se trata más específicamente en "la capacidad para tomar una decisión racional"58.

La capacidad relevante a los efectos de la justificación del paternalismo es una noción de todo o nada. Para que la determinación del grupo de los incapaces se haga razonablemente, es necesario aceptar la propuesta de

${ }^{53}$ Dworkin, Ronald: Ética privada e igualitarismo político, cit., p. 144.

${ }^{54}$ Véase: Garzón Valdés, Ernesto: “¿Es éticamente justificable el paternalismo jurídico?”, cit., pp. 165 y ss. Ernesto Garzón utiliza el término "incompetencia” y no el de "incapacidad”. Con el mismo sentido, utilizaré sin embargo este segundo término porque creo que se ajusta más a la tradición jurídica del Derecho privado español.

${ }^{55}$ Esta incapacidad en sentido estricto hace referencia al estado de un individuo cuyas facultades están dañadas o no desarrolladas, de forma temporal o permanente.

${ }^{56}$ Feinberg, Joel: Harm to Self, cit., p. 28. 165.

${ }^{57}$ Garzón Valdés, Ernesto: “¿Es éticamente justificable el paternalismo jurídico?”, cit., p.

${ }^{58}$ Gert, Bernard, Charles M. Culver y K. Danner Clouser: Bioethics. A Return to Fundamentals, cit., p. 137. 
Ernesto Garzón y Daniel Wikler ${ }^{59}$ de partir de un concepto de "capacidad básica”, es decir, serían capaces todos aquellos que tienen la capacidad mínima necesaria para afrontar las tareas y desafíos que plantea la consecución del bienestar individual. Otra forma de decir lo mismo es indicando que un estándar adecuado de la capacidad debe dejar a la mayoría de los adultos del lado de la capacidad.

Creo que tienen razón Allen Buchanan y Dan Brock cuando defienden que "el nivel de capacidad que es exigible para tomar una decisión en particular debe ajustarse a las consecuencias de actuar conforme a esa decisión” ${ }^{60}$. Esta estrategia de la escala móvil en el nivel de capacidad mínima exigible se apoyaría en la idea de que las decisiones que conllevan graves consecuencias son más complejas (me inclino a pensar que es así) y en que, como sostiene Joel Feinberg, el sentido común aconsejaría manejar este estándar móvil. Las reglas prácticas que este último autor nos propone para determinar el estándar de voluntariedad aplicable ${ }^{61}$, se podrían adaptar a la concepción general de la incapacidad de la siguiente manera:

1) Cuanto mayor sea el riesgo de una conducta, tanto mayor debe ser el grado de capacidad requerido para permitir la conducta.

2) Cuanto más irremediable sea el daño arriesgado, tanto mayor debe ser el grado de capacidad requerido para permitir la conducta ${ }^{62}$.

3) El estándar de capacidad debe adaptarse de otras maneras a las diversas circunstancias especiales ${ }^{63}$.

De acuerdo con estas reglas, el estándar de capacidad exigible para, por ejemplo, rechazar un tratamiento cuando este rechazo puede suponer la muerte debe ser más alto que el estándar de capacidad exigible para un rechazo cuyas consecuencias son menos graves. La capacidad mínima exi-

\footnotetext{
${ }^{59}$ Véase: Wikler, Daniel: “Paternalism and the Mildly Retarded”, en Sartorius, Rolf: $P a$ ternalism, cit.

${ }^{60}$ Brock, Dan y Allen Buchanan: Deciding for Others, ed. Cambridge University Press, Cambridge, 1989, p. 52. Junto a este trabajo, hay otra elaboración muy destacada de la "escala móvil” que se debe a James F. Drane, véase: Drane, James F.: “Competence to Give an Informed Consent. A Model for Making Clinical Assessments”, en Journal of the American Medical Association, 252 (1984), pp. 925-927; y Drane, James F.: The Many Faces of Competency, en Hastings Center Report, 1985, pp. 17-21.

${ }^{61}$ Joel Feinberg propone que las únicas interferencias paternalistas justificadas son aquellas que tratan de evitar a los individuos las consecuencias dañosas de sus acciones, siempre que estas acciones sean insuficientemente voluntarias o una intervención temporal sea necesaria para determinar la voluntariedad de las acciones. Véase: Feinberg, Joel: Harm to Self, cit.

${ }^{62}$ Gerald Dworkin considera como uno de los factores relevantes para la justificación del paternalismo que se trate de evitar "decisiones que suponen cambios irreversibles”, en Dwokin, Gerald: “Paternalism”, en Sartorius, Rolf: Paternalism, cit., p. 31.

${ }^{63}$ Feinberg, Joel: Harm to Self, cit., p. 114.
} 
gible para rechazar un tratamiento vital sería mayor que para rechazar un tratamiento no vital. A su vez, creo que estas mismas reglas podrían manejarse con respecto a la prueba de la capacidad y, por tanto, la prueba de la capacidad en una decisión de vida o muerte debe ser más exigente que en una decisión de menor gravedad.

Un tópico importante en torno al manejo de la noción de capacidad dice que la incapacidad de un sujeto debe poder determinarse con independencia del contenido de su decisión. Todos los autores coinciden en que decir que la decisión $\mathrm{x}$ de $\mathrm{B}$ no debe ser respetada porque $\mathrm{B}$ es incapaz, cuando la única razón para juzgar a $\mathrm{B}$ incapaz es que ha tomado la decisión $\mathrm{x}$, es una forma de "hacer trampas" con la noción de incapacidad. De ahí que se exija que la capacidad se determine por medio de un test independiente que evalúe las capacidades de los individuos para tomar ciertas decisiones. Si bien lo anterior es correcto, me parece que también lo sería afirmar que la capacidad o incapacidad de B para decidir x depende de si x es racional, siempre que se entienda (correctamente) que decir que " $x$ es una decisión racional para B” supone hacer un juicio que pone en relación el contenido de la decisión $\mathrm{x}$ con las creencias, preferencias y los procesos de formación de creencias y preferencias del propio $\mathrm{B}$.

De acuerdo con la teoría estricta de la racionalidad, la racionalidad de un acto depende de las propias creencias y deseos del agente ${ }^{64}$. El requisito fundamental de racionalidad sería la consistencia de las creencias y de los deseos. Para determinar si una acción $\mathrm{x}$ de $\mathrm{B}$ es irracional en este sentido estricto, debemos conocer las creencias y deseos relevantes de B para la acción $\mathrm{x}$ y juzgar si son inconsistentes. Una vez que hemos determinado que $\mathrm{x}$ es irracional para B en este sentido estricto, es plausible sostener que hemos determinado, a la vez, que B está en una situación de incapacidad.

De acuerdo con una teoría amplia de la racionalidad, un sujeto que actúa consistentemente de acuerdo con sus creencias y deseos consistentes puede actuar todavía irracionalmente. Aquí se trata de ver la racionalidad sustantiva de los deseos y las creencias y no, únicamente, su consistencia interna. Jon Elster propone que "valoremos la racionalidad amplia de las creencias y los deseos observando el modo en que están conformados”65. Los deseos y las creencias irracionales, en este sentido, son aquellos que tienen algún "tipo erróneo de historia causal”66. En positivo, la “capacidad”

\footnotetext{
${ }^{64}$ Sobre la concepción estricta y amplia de la racionalidad sigo a Elster, Jon: Uvas amargas. Sobre la subversión de la racionalidad, cit. Véase, igualmente: Davidson, Donald: Essays on Actions and Events, ed. Oxford University Press, 1980.

${ }^{65}$ Elster, Jon: Uvas amargas. Sobre la subversión de la racionalidad, cit., p. 29.

${ }^{66}$ Ibídem.
} 
necesaria para formar creencias racionales sería el "buen juicio”, es decir, "la capacidad de sintetizar información vasta y difusa que más o menos claramente trata acerca del problema que nos ocupa, de tal modo que no haya un conjunto de elementos al que se le dé una importancia indebida"67; mientras que la "capacidad" necesaria para formar preferencias racionales sería la “autonomía”. Jon Elster no encuentra una forma satisfactoria de definir la autonomía en positivo por lo que propone entenderla "como un mero residuo, como aquello que queda una vez hemos eliminado los deseos que han sido modelados por algunos de los mecanismos de la breve lista de preferencias irracionales" ${ }^{\text {, }}$, a lo que añade, “de modo similar, la cualidad del juicio para las creencias debe ser entendida como la ausencia de distorsiones e ilusiones”"69.

Al igual que ocurre con el concepto de “decisión estrictamente irracional”, cuando se trata de una “decisión sustancialmente irracional” no basta únicamente con conocer el sentido de la decisión (por ejemplo, suicidarse o no), sino que hay que indagar el origen de la misma, a la búsqueda de elementos distorsionadores del buen juicio o de la autonomía. Por esto, a la vez que podemos decir que el juicio de incapacidad sobre el sujeto B en relación con la decisión $\mathrm{x}$ depende de la racionalidad, formal o sustancial, de $x$, podemos decir que el juicio de incapacidad no depende únicamente del contenido de la decisión $\mathrm{x}$.

Un presupuesto importante de las anteriores consideraciones es que, como sostiene Jon Elster, "entre la teoría estricta de lo racional y la teoría completa de lo verdadero y de lo bueno hay suficiente espacio y necesidad para una teoría amplia de la racionalidad"70. Esto es importante porque nos permite entender la pretensión del paternalista de diferenciarse del moralista, cuya preocupación no sería la racionalidad de las acciones, en los sentidos explicados, sino la corrección moral de las mismas.

A partir de esta caracterización general de la noción de capacidad básica, lo más importante es determinar qué tipos de factores pueden interferir con la misma. Una primera clasificación de estos factores resultaría de aplicar una doble distinción: (1) factores de incapacidad que afectan a aspectos cognitivos o volitivos, y (2) factores de incapacidad que son consecuencia

${ }^{67}$ Elster, Jon: Uvas amargas. Sobre la subversión de la racionalidad, cit., p. 30.

${ }^{68}$ Elster, Jon: Uvas amargas. Sobre la subversión de la racionalidad, cit., p. 41. Un resumen de la concepción de la autonomía de Jon Elster puesta en relación con los presupuestos del liberalismo político puede verse en De Páramo, Juan Ramón: Tolerancia y liberalismo, cit., pp. 71-75.

${ }^{69}$ Elster, Jon: Uvas amargas. Sobre la subversión de la racionalidad, cit., p. 41.

${ }^{70}$ Elster, Jon: Uvas amargas. Sobre la subversión de la racionalidad, cit., p. 29. 
de elementos externos o internos ${ }^{71}$. Al entrecruzar estas dos distinción obtendríamos la siguiente tabla:

Tipos de incapacidad (I)

$\begin{array}{ccc} & \text { Origen interno } & \text { Origen externo } \\ \text { Aspectos cognitivos } & \text { I } & \text { III } \\ \text { Aspectos volitivos } & \text { II } & \text { IV }\end{array}$

Conviene advertir que en un sentido estricto de incapacidad (que es el utilizado por los civilistas), ésta se refiere únicamente a I y II, es decir, a aquello que puede considerarse un estado o condición del sujeto (permanente o transitoria) que afecta a la capacidad de un individuo para tomar decisiones racionales, en ausencia de una causa externa que esté produciendo esos mismos efectos. Las incapacidades tipo III y IV serían incapacidades (básicas) relativas, en el sentido de que la desaparición de la causa externa que interfiere con los aspectos cognitivos o volitivos supone que el individuo recobra la capacidad.

Cada uno de estos tipos de incapacidad puede dar lugar a un tratado independiente. Aquí quisiera tan sólo hacer algunos comentarios que pudieran ser de utilidad para la justificación de interferencias paternalistas.

\section{A) Incapacidades tipo I}

En primer lugar, hay que señalar que las consecuencias dañosas de una acción intencional pueden considerarse como "auto-infligidas”, aunque el agente no tuviera la intención de provocar esas consecuencias. Éste es un punto importante, porque el factor de la ignorancia puede jugar tanto en la descripción de las acciones como en la determinación de su voluntariedad: una acción de auto-daño “involuntaria” en el sentido de afectada por la presencia del factor de la ignorancia o del error puede ser considerada, sin embargo, "voluntaria” en el sentido de que el daño es una consecuencia de una acción intencional ${ }^{72}$.

La ignorancia y el error están siempre presentes en la actividad humana. Por esto es necesario hablar siempre, a los efectos de la justificación del paternalismo, de ignorancia o error relevante. Podría decirse que la ignorancia y el error son relevantes en un acto de auto-daño cuando el agente hubiera

\footnotetext{
${ }^{71}$ Elster, Jon: Uvas amargas. Sobre la subversión de la racionalidad, cit., p. 29.

72 Éste sería el sentido en el que podemos decir que los daños que se ha causado un individuo al consumir una droga peligrosa, cuando desconocía la nocividad de la sustancia, son “auto-infligidos”.
} 
actuado de otra manera si sus creencias no hubieran estado afectadas por el error o la ignorancia.

Este tipo I de incapacidad se caracterizaría porque afecta a los aspectos cognitivos del proceso de adopción de decisiones racionales y se manifestaría siempre por la presencia de

a) Ignorancia relevante, cuando ésta no se debe al ocultamiento de información por otro: por ejemplo, la ignorancia de los efectos de las drogas, y/o

b) Creencias erróneas relevantes, cuando éstas no se deben al engaño de otro: por ejemplo, la creencia en que hay una probabilidad más alta de la real de ganar en la lotería (entre estas creencias erróneas merece la pena destacar a las creencias inconsistentes del individuo: por ejemplo, mantener simultáneamente la creencia de que "llevar un amuleto no me traerá suerte" y de que "los amuletos traen suerte a aquellos que no creen que les traerá suerte”).

Ante la presencia de estos factores de incapacidad, el anti-paternalista suele indicar que lo único que se requiere para retornar a los sujetos a la capacidad es proporcionarles la información necesaria. Sin embargo, el paternalista replicará que, en primer lugar, esto no siempre es así y, en segundo lugar, que podría concebirse todo un conjunto de medidas paternalistas orientadas a asegurarse que los individuos tengan la información relevante. Una de estas medidas sería, a mi juicio, la campaña de información sobre los efectos del consumo de tabaco consistente en incluir en los paquetes de tabaco avisos sobre estos efectos. La medida va más allá de la facilitación de información adecuada sobre el tabaco, consiste más bien en confrontar al fumador con las consecuencias de su hábito, porque casi irremediablemente al coger sus cigarrillos verá los avisos (salvo que, como hacen algunos fumadores, tapen estos avisos metiendo el paquete de tabaco en una tabaquera). Este caso muestra dos aspectos: primero, que hay medidas paternalistas que consisten en imponer la información (esta sería, por cierto, una parte de la doctrina del consentimiento informado en bioética cuando los pacientes prefieren no saber) y, segundo, que los individuos pueden no utilizar la información de que disponen.

Entre las causas más frecuentes de este tipo de incapacidad I se pueden señalar:

I.a) Enfermedades mentales: tales como los trastornos psicóticos (esquizofrenia, demencia, formas extremas de depresión) que provocan una pérdida de contacto con la realidad; trastornos neuróticos como la paranoia, que se caracteriza por sostener creencias falsas de forma resistente a toda crítica; el retraso mental; la anorexia nerviosa, que se caracteriza por la dismorfofobia (imagen distorsionada del propio cuerpo); y, en general, 
cualquier trastorno mental que dificulte las tareas de comprender, apreciar o procesar información.

I.b) Deficiencias graves de educación en adultos ${ }^{73}$.

I.c) Inmadurez.

I.d) Estados de intoxicación por sustancias psicoactivas.

I.e) Creencias que resultan de una racionalización de la esperanza: por ejemplo, la mujer maltratada que cree que su compañero maltratador va a dejar de maltratarla en el futuro (la mujer termina creyendo lo que quiere creer).

I.f) Errores inferenciales: por ejemplo, el que cree que después de haber sobrevivido a un grave accidente de tráfico las probabilidades de que le "toque” de nuevo son mucho menores que antes del accidente (es la idea que expresa la frase "yo ya he tenido mi parte de mala suerte”).

B) Incapacidades tipo II

Este tipo II de incapacidad se caracterizaría porque afecta a los aspectos volitivos del proceso de adopción de decisiones racionales y se manifestaría siempre por la presencia de preferencias irracionales (ya sean "irracionales” según una concepción estricta de la racionalidad o de acuerdo con una concepción amplia de la racionalidad).

Entre las causas más frecuentes de este tipo II de incapacidad se pueden señalar las siguientes:

II.a) Preferencias inconsistentes: por ejemplo, el fenómeno de la debilidad de la voluntad.

II.b) Enfermedades mentales: en particular, los trastornos neuróticos como las fobias, el comportamiento obsesivo-compulsivo, la hipocondria, etc.

II.c) Inmadurez

II.d) Estados de intoxicación por sustancias psicoactivas.

II.e) Adicciones

II.f) Formación de preferencias adaptativas: un proceso causal que ocurre de manera no consciente por el que el individuo ajusta sus voliciones a sus posibilidades (por ejemplo, la mujer que prefiere ser "ama de casa" a otras opciones laborales cuando la sociedad no permite el ingreso de la mujer en el mercado de trabajo $)^{74}$.

\footnotetext{
${ }^{73}$ Téngase en cuenta que estas consideraciones se limitan a la capacidad básica, lo cual supone que carecen de ella aquellas personas que no tienen aquellos conocimientos que son normales en la mayoría y que permiten satisfacer las necesidades básicas y enfrentarse a los problemas más cotidianos de la vida.

${ }^{74}$ Véase: Elster, Jon: Uvas amargas. Sobre la subversión de la racionalidad, cit., pp. 159 y ss.
} 
II.g) Cambio de preferencias por estructuración: un proceso que, nos aclara Jon Elster, “ocurre cuando cambia el relativo atractivo de las opciones cuando la situación de elección es reestructurada de tal modo que racionalmente no se vean diferencias entre ellas” (por ejemplo, quien compra un producto cuando por hacerlo le regalan otro, pero no compraría ambos productos por separado aun cuando la suma del precio de los dos fuera igual al precio del primer producto con regalo $)^{75}$.

C) Incapacidades tipo III

Este tipo de incapacidad se manifiesta de la misma manera que la incapacidad tipo I, pero la causa de la incapacidad es externa al individuo. Las causas de este tipo III de incapacidad son: III.a) el ocultamiento de información, y III.b) el engaño.

\section{D) Incapacidades tipo IV}

Este tipo de incapacidad se manifiesta de la misma manera que la incapacidad tipo II, pero la causa de la incapacidad es externa al individuo. Las causas de este tipo IV de incapacidad son: IV.a) las amenazas, y IV.b) las ofertas coactivas (cuando el ofertante ha creado las condiciones coactivas) ${ }^{76}$.

\subsection{El consentimiento hipotético racional a la medida}

Esta condición de justificación tiene dos partes: En primer lugar, se exige que se pueda presumir racionalmente que B prestaría su consentimiento a la posibilidad general de ser tratado paternalistamente por A en ciertas ocasiones. Lo que me parece fundamental resaltar es que este juicio racional depende del contexto de la relación paternalista y, en particular, de quiénes sean los sujetos de la relación paternalista. Si no me equivoco, el principal argumento de muchos autores liberales contra el paternalismo consistiría en afirmar que aceptar casos de paternalismo justificado cuando el agente A es el Estado no es racional (éste sería el “argumento más fuerte”77 de John S. Mill contra el paternalismo). Por otro lado, habría autores que, como John Rawls, han sostenido que aceptar casos de paternalismo estatal sí sería racional $^{78}$ o que, como Ernesto Garzón, han sostenido, incluso, que sería irracional no aceptarlos ${ }^{79}$.

${ }^{75}$ Elster, Jon: Uvas amargas. Sobre la subversión de la racionalidad, cit., p. 42.

${ }^{76}$ Feinberg, Joel: Harm to Self, cit., p. 246.

${ }^{77}$ Véase: Mill, John S.: Sobre la libertad. cit., p. 164.

${ }^{78}$ Rawls, John: Teoría de la Justicia, ed. Fondo de Cultura Económica, México, 1997, pp. 234 y ss.

${ }^{79}$ Garzón Valdés, Ernesto: “¿Es éticamente justificable el paternalismo jurídico?”, cit. 
Convendría precisar, en primer lugar, que el problema se plantea principalmente con el paternalismo estatal (jurídico o no) y no tanto con el paternalismo jurídico no estatal. La razón de esta diferencia reside en la distinción apuntada anteriormente entre contextos cooperativos y conflictivos de paternalismo. Creo que todo el mundo estaría de acuerdo en que es racional admitir la posibilidad de casos de paternalismo justificado en contextos cooperativos y que esa posibilidad debe verse reflejada en las leyes, de manera que se permita jurídicamente lo que parece moralmente justificado.

Qué constituya un contexto cooperativo depende de las circunstancias concretas. La familia, como se dijo, es el contexto cooperativo por excelencia, pero hay muchos casos en la realidad en que no es así. Confiar a la institución de la familia el cuidado y educación de los menores parece más razonable si se piensa que de esta manera se limita el paternalismo a contextos cooperativos (donde tiene más probabilidades de ser genuino y exitoso paternalismo) en detrimento de contextos más amplios y conflictivos. Igualmente, la práctica médica tradicional del médico de cabecera puede ser interpretada como un contexto de paternalismo cooperativo, en el cual el conocimiento íntimo del paciente por parte del médico capacitan a este último para (1) conocer qué evita daños realmente al paciente, (2) determinar con exactitud si el paciente esta en una situación de incapacidad y (3) juzgar si el paciente hubiera consentido a la intervención en el caso de no estar en una situación de incapacidad básica. La crisis de este modelo y el desarrollo de formas de relación médico-paciente cada vez más despersonalizadas acerca la práctica de la medicina a un contexto de paternalismo conflictivo. Finalmente, lo mismo puede decirse del paternalismo industrial (que podría definirse como aquel en el que el agente $\mathrm{A}$ es el empresario y el sujeto B son los trabajadores): conforme el ambiente de la empresa es menos familiar o gremial y más capitalista, el conflicto de intereses entre ambas partes se agudiza y el contexto para el paternalismo se torna conflictivo.

Pues bien, la pregunta que quisiera plantear es la siguiente: ¿Es racional aceptar la posibilidad de que un Estado democrático y constitucional ejerza el paternalismo, tal y como se ha definido, sobre los ciudadanos, cumplidas las otras condiciones de justificación? Asumiré que para responder a esta pregunta correctamente debe, en primer lugar, operarse con una regla maximin de decisión ${ }^{80}$, en segundo lugar, debe aceptarse el hecho de que todos los seres humanos se hallan en una situación de incapacidad en algún momento de su vida (algunos permanentemente) y que en esos momentos de incapacidad pueden dañar seriamente sus intereses y, en tercer lugar,

${ }^{80}$ Una sencilla descripción de esta regla puede encontrarse en: Rawls, John: Teoría de la justicia, cit., pp. 150 y ss. 
debe entenderse que la pregunta se plantea en términos generales (no se pregunta por lo que sería racional para algún individuo en concreto, sino por lo que sería racional aceptar por los ciudadanos). De acuerdo con esta regla, debemos considerar, en primer lugar, la peor de las situaciones posibles y, en segundo lugar, juzgar preferible aquella opción que mejora esta situación. La adopción de la regla maximin se justifica por la desconfianza ante la posibilidad de que el Estado actúe como padre, dado el contexto de intereses en conflicto en el que se desenvuelve la acción estatal. Veamos, cómo operaría esta regla, en relación con algunos de los supuestos más importantes de paternalismo.

Pensemos, en primer lugar, en la irrenunciabilidad de los derechos. Es racional que los ciudadanos quieran tener sus derechos garantizados jurídicamente, pero de ahí no se sigue sin más que sea racional, además, que esos derechos sean también irrenunciables para los mismos beneficiados por ellos. Para aplicar la regla maximin debemos juzgar cuál es la mejor de estas dos peores situaciones posibles: una, en la que renunciamos a algunos de nuestros derechos porque somos coaccionados, engañados o, en general, nos hallamos en una situación de incapacidad básica y, otra, en la que no se nos permite renunciar a alguno de nuestros derechos cuando tenemos buenas razones para ello. Hay que tener en cuenta que por "renunciar a un derecho" me refiero a "renunciar a su titularidad" no a "no ejercer un derecho": por ejemplo, renunciar al derecho a la vida supone dejar en manos de otro la decisión de si debo continuar viviendo o no, mientras que no ejercer el derecho a la vida supone decidir suicidarme o permitir a otro que me mate. A mi juicio, la decisión racional sería admitir la irrenunciabilidad a los derechos en tanto que se permita su no ejercicio.

Un paso adelante sería considerar si alguno de nuestros derechos irrenunciables deberían ser, además, derechos de ejercicio obligatorio. Se trataría de derechos cuyo beneficio para el titular debe ser impuesto. El ejemplo más común de este tipo de derechos (en el contexto de nuestro sistema jurídico) sería el derecho a la educación, pero, como ha señalado Liborio Hierro, habría otros tales como el derecho de defensa, el habeas corpus, la igualdad ante la ley, etc. ${ }^{81}$. Este tipo de derechos serían "derechosobligación”, es decir, “derechos” porque fundamentan una pretensión frente a otros (particularmente al Estado) de proporcionar los medios necesarios

${ }^{81}$ Hierro, Liborio: "Derechos humanos o necesidades humanas. Problemas de un concepto”, en Sistema, 46 (1982), p. 48. 
para su satisfacción y de no interferencia con su ejercicio y "obligación” porque el titular no puede elegir no ejercitarlo ${ }^{82}$.

La fundamentación de estos derechos-obligación pasa por la teoría de las necesidades básicas. Sobre este concepto de "necesidad básica” quisiera destacar tan sólo dos propiedades que me parecen relevantes para juzgar sobre la justificación del paternalismo estatal: primero, los bienes básicos o primarios tienen un carácter esencialmente instrumental y es plausible sostener que por sí solos no tienen valor alguno y, segundo, hay situaciones dramáticas en las que la satisfacción de una necesidad básica conlleva la insatisfacción de otra. Estas consideraciones menoscaban la posición de que cabe fundar una presunción general de que todo individuo que, con sus acciones y omisiones, frustra la satisfacción de sus necesidades básicas está en una situación de incapacidad básica y, de ahí, la necesidad de tener en cuenta la segunda parte de la condición de justificación que se está comentado: que se pueda presumir racionalmente que B prestaría su consentimiento a la acción paternalista en concreto, si no estuviera en una situación de incapacidad básica.

El caso más claro a este respecto sería el de la configuración del derecho a la vida como un “derecho-obligación”. La prohibición penal de la práctica de la eutanasia se apoya, en ocasiones, en una concepción del derecho a la vida como un derecho-obligatorio. Sin embargo, los defensores de la prohibición desatienden sistemáticamente un aspecto relevante de la cuestión: la situación en la que queda la persona a la que se le niega la eutanasia. Ésta situación conlleva, por un lado, una insatisfacción de necesidades básicas, como la de "no sufrir graves padecimientos permanentes y difíciles de soportar", y, por otro lado, resta valor instrumental a la vida cuando "conduce (en un plazo breve) necesariamente a la muerte”. En este contexto me parece implausible una presunción general de que los solicitantes de eutanasia son incapaces. A esto hay que añadir que el desarrollo de las ciencias biomédicas ha multiplicado las ocasiones en las que estas situaciones se pueden dar. No obstante, se podría contra-argumentar diciendo que la regla maximin hace preferible asumir el riesgo de quedar entre la espada y la pared de la enfermedad y la prohibición, al riesgo de que se nos practique la eutanasia cuando no hemos consentido válidamente por hallarnos en una situación de

\footnotetext{
82 Sobre el concepto de “derechos” aplicable a estos casos, véase: Feinberg, Joel: "Voluntary Euthanasia and the Inalienable Right to Life”, en Philosophy \& Public Affairs, 7(1978), $\mathrm{n}^{\circ}$ 2 (trad. al castellano en Anuario de Derechos Humanos, 7(1990), pp. 61-88); Hierro, Liborio: "Derechos humanos o necesidades humanas. Problemas de un concepto”, cit.; y MacCormick, Neil: “Children's rights: a test-case for theories of right”, en MacCormick, Neil: Legal Rights and Social Democracy. Essays in Legal and Political Philosophy, ed. Clarendon Press, Oxford, 1982, pp. 154-166.
} 
incapacidad básica. Ahondando en este argumento, se podría añadir que los enfermos terminales se encuentran con frecuencia en una situación de incapacidad básica. Los abolicionistas replicarían, por su parte, que este riesgo puede ser atenuado por medio de procedimientos de control. A mi juicio, esta última es la posición más correcta.

Pensemos, sin embargo, en el derecho-obligación de comparecer en juicio con la asistencia de un abogado. Eventualmente este derecho puede imponerse contra la voluntad de su titular y en su propio beneficio. Generalmente, cuando el que desea renunciar a su derecho tiene una formación jurídica acreditada (él mismo es abogado o tiene los estudios de Derecho) se le permite hacerlo, de manera la interferencia paternalista se limitaría a aquellos que no desean ser representados y asesorados jurídicamente cuando no tienen los conocimientos jurídicos necesarios para defender sus propios intereses. Es fácil advertir que si el individuo desea ser castigado o que se oiga su propia voz, la obligación de contar con asistencia letrada no se lo impedirá. En realidad, este derecho lo único que obstaculiza es cumplir estos propósitos en ignorancia de las circunstancias legales. Aquí estaríamos, me parece, ante un paternalismo estatal ante el que individuos racionales consentirían.

En general, podría decirse que es claramente racional consentir al paternalismo estatal que se orienta a impedir que los individuos persigan sus intereses en ignorancia de circunstancias relevantes e, igualmente, aquellos procedimientos de control orientados a garantizar que el sujeto que toma sus decisiones no lo hace en un estado de incapacidad básica.

En la tradición del pensamiento político, hay doctrinas caracterizadas por la asunción de un paternalismo generalizado: por ejemplo, el gobierno de los filósofos de Platón, la monarquía patriarcal de John Filmer, el despotismo ilustrado (o absolutismo ilustrado), la dictadura del proletariado o el gobierno de los científicos de la conducta propuesto por B. F. Skinner; y doctrinas caracterizadas por una estricto anti-paternalismo: por ejemplo, el Estado mínimo de Robert Nozick. Todas ellas, de un lado y otro, me parecen irrazonables. La asunción de un limitado paternalismo constituiría un elemento importante en el test de aceptabilidad de las consecuencias de una doctrina política. Por ello creo que la reflexión sobre el paternalismo es interesante y confío en que las anteriores consideraciones puedan ser útiles a la misma. 
$\triangle \quad$ DOXA 28 (2005) 